\title{
EL PROFESORADO UNIVERSITARIO DESDE UNA PERSPECTIVA DE GÉNERO
}

\author{
Azucena Hernández Martín \\ Profesora de la Universidad \\ de Salamanca, España \\ Ana García-Valcárce Muñoz-Repiso \\ Profesora de la Universidad \\ de Salamanca, España \\ María Cruz Sánchez Gómez \\ Profesora de la Universidad \\ de Salamanca, España
}

\author{
Recibido 7-I-2004 • Aceptado 9-III-2004
}

\begin{abstract}
Resumen: En este artículo presentamos un estudio de las instituciones universitarias de Castilla $y$ León, y más concretamente de su personal docente, desde una perspectiva de género. Con la finalidad de que sirva como marco de referencia efectuamos, en primer lugar, algunas reflexiones sobre la relación entre el género, la formación y las posibilidades de acceso laboral; en segundo lugar recogemos y comentamos algunos datos en torno a la evolución experimentada por la Universidad Española, en relación con la participación de la mujer entre su profesorado. Este mismo aspecto es revisado también en un otro epígrafe del artículo, en el que nos centramos ya propiamente en las instituciones universitarias de Castilla y León. Por último, describimos la investigación que sobre género y función docente hemos desarrollado durante el curso académico 2001-2002 en la citada comunidad autónoma, presentando los principales resultados al respecto.
\end{abstract}

Palabras clave: Universidad, Profesorado, Género, Función Docente, Desigualdad.

\section{Introducción}

Hoy en día, pese a los avances realizados en las sociedades democráticas sobre la igualdad de oportunidades de la mujer, aún estamos lejos de poder alcanzar las cuotas de participación que poseen nuestros compañeros varones. Es obvio que esta finalidad sólo es alcanzable siempre y cuando se establezcan las medidas políticas y legales oportunas, aunque no sólo, pues la implantación de la ley no tiene por qué ir pareja a los cambios de mentalidad social necesaria que permitan, de una vez por todas, la visibilidad de las mujeres y el reconocimiento de su contribución en todas las esferas de la cotidianeidad.

El estudio que presentamos en estas páginas pretende efectuar el análisis de las instituciones universitarias de Castilla y León, y más concretamente de su personal docente, desde la perspectiva de género. Entendemos que la profesión docente universitaria es un ámbito de observación significativo para el estudio de la relación género-trabajo. En ella, por pertenecer a un 


\begin{abstract}
In this article we present a study of the University of Castilla and the University of León. More concretely we make reference to their teaching staff from he perspective of gender. With the idea in mind that this article serves as a framework of reference we made, in the first place, some reflections on the relationship between gender, formation and the possibilities for access to work. In the second place, we collected some data about the evolution experienced by the Spanish University in connection with the participation of the female faculty. This aspect is also discussed in a excerpt of the article in which attention is focused mainly on Castilla and León higher learning institutions. Lastly, we describe the research done on gender and teaching performance in the aforementioned university environment during the 2001 to 2002 period. We offer the corresponding results.
\end{abstract}

Key words: University, Faculty, Gender, Educational Function, Inequality. status medio-alto, se pueden producir los mayores cambios para concluir el proceso de igualdad de oportunidades.

Vamos a presentar en primer lugar, apoyándonos en los numerosos estudios realizados sobre el tema, tanto a nivel nacional como internacional, algunas reflexiones sobre la relación entre el género, la formación y las posibilidades de acceso laboral; en segundo lugar, y acercándonos ya a la temática del artículo, revisaremos algunos datos en torno al proceso seguido por la universidad española, en relación a los índices de participación de la mujer entre su profesorado. Nuestro recorrido se centrará en la exposición de los datos recabados, a partir de las aportaciones de diversas investigaciones realizadas y del Instituto Nacional de Estadística, desde mediados de los 70 hasta la actualidad (Instituto de la Mujer, 1996; Almarcha et al. 1994; Grañeras et al. 1999 y CIDE, 1988, 1992 y 2001). La importancia de estudiar este aspecto radica en que nos va a permitir contrastar las situaciones pasadas y actuales, y así determinar el avance conseguido en la incorporación de las docentes a dicha institución.

Realizaremos también un breve análisis retrospectivo, y desde una perspectiva de género, de la evolución experimentada por el profesorado universitario de la Comunidad Autónoma de Castilla y León -territorio donde se circunscribe el trabajo de investigación que hemos desarrollado-, durante el periodo comprendido entre 1995-2000. Por último, expondremos los principales objetivos y aspectos metodológicos de la investigación que hemos desarrollado al respecto durante el curso académico 2001-2002, así como los principales resultados obtenidos.

\section{Género: Formación y acceso laboral}

La inserción en el mundo laboral para cualquier persona o colectivo, marginal o no, supone una condición imprescindible 
para su reconocimiento social, por cuanto que implica su participación en la vida económica y social. Ésta, entre otras posibilidades de desarrollo, ha estado tradicionalmente vetada a las mujeres provocando, en cierta medida, su aislamiento social.

La permanencia de esta forma de marginación de las mujeres durante siglos hay que buscarla en las limitaciones de acercamiento a la cultura y a la educación de las que también han sido objeto, y que por desgracia, hoy en día aún perduran en algunos países. El bloqueo y el sesgo de conocimientos que les ha sido impuesto en el ámbito educativo conlleva, sin duda alguna, la introyección de toda una serie de creencias y valores, en nada ajenas a la construcción de sus comportamientos sociales o roles, y a la percepción depreciada de sí mismas como personas.

Pero parece que este panorama hasta ahora dibujado está cambiando paulatinamente. La población femenina está cada vez más presente en todas las parcelas de la sociedad. A lo largo del siglo XX se han conseguido grandes logros, no sin esfuerzo por parte de algunas que han luchado a brazo partido por salir de la situación de segregación a la que estaban sometidas. Entre ellos debemos destacar la inserción educativa, profesional y política.

Sin embargo, aún queda mucho para que las mujeres tengan las mismas oportunidades que poseen sus compañeros, especialmente en el ámbito laboral. El mundo del trabajo, como se deduce de los resultados de diversas investigaciones, ha sido y sigue siendo donde se detectan mayores resistencias a su integración. Este es un contexto en el que la segregación se manifiesta con mayor crudeza y donde persisten obstáculos relacionados con la discriminación externa, los procesos de autolimitación y la discriminación interna (Barberá et al. 1998). El análisis de la división sexual del trabajo ha explicitado diversos tipos de segregación sexual: la vertical y la horizontal; mientras que la primera se refiere a la concentración de la mano de obra femenina en las profesiones de menor cualificación, la horizontal indica su dedicación a tareas y labores específicas.

Aún hoy se siguen oyendo casos en los que se impide el acceso a un puesto de trabajo por cuestiones ligadas al sexo y al género, como la maternidad, el previsible absentismo laboral por el cuidado de los hijos, la presunción de menor cualificación que un hombre, ... Discriminaciones que son más frecuentes y visibles en la empresa privada, lo que no quiere decir que la empresa pública esté libre de tales prácticas; en todo caso, pueden estar revestidas de mayor sutileza. En este orden de cosas, si bien podemos determinar la influencia de factores externos de discriminación como el dominio del hombre en la esfera laboral y la ausencia de perfiles femeninos a imitar por las mujeres, no hemos de ocultarnos la presencia de otros componentes psicoeducativos asumidos por las propias mujeres, tal como la aceptación incondicional de roles socialmente femeninos, que con frecuencia dan lugar a su autolimitación (sentimientos de inferioridad, inseguridad, falta de ambición, baja autoestima, aceptación y justificación del rol masculino). Estamos hablando del impacto psicológico inconsciente que las organizaciones patriarcales tienen en la mujer constituyendo una barrera muy importante para su desarrollo personal y social (Martín y Delgado, 2000). Ello justifica y realza el papel de la educación no sólo como medio de cualificación laboral de la mujer, lo que en la actualidad es una evidencia (como veremos más adelante), sino como concienciadora de situaciones de injusticia en la que se mueve el colectivo femenino y, al mismo tiempo también, como transformadora de desequilibrios en la estructura social de género.

Pese a todo, es un hecho el avance acaecido en materia laboral en las últimas décadas en lo que atañe al incremento del colectivo femenino. La incorporación de la mujer al trabajo extradoméstico se considera 
deseable por cuanto que significa un paso más en la igualdad entre hombres y mujeres, la mejora de su bienestar material, autoestima e independencia y una mayor participación social (Casas, 1994). No obstante, la realidad a la que se enfrentan muchas trabajadoras no responde en demasiadas ocasiones a esos excelentes auspicios.

Por el contrario, informes a nivel mundial ponen de manifiesto el desequilibrio existente entre géneros en la ocupación jerárquica de los puestos de trabajo. De modo que las mujeres mayoritariamente desempeñan tareas de menos prestigio social y en condiciones más precarias. A nivel mundial se indica que si bien el empleo de trabajadoras ha aumentado en la mayoría de los países desde mediados de los 80 a finales de los 90, ese incremento no ha supuesto la mejora en la calidad de los empleos (UNIFEM, 2000).

Por otra parte, se ha de tener en cuenta que la actividad laboral en el caso de la mujer ha de aunarse con las tareas domésticas y familiares que ésta realiza casi con exclusividad, afrontando una doble jornada de trabajo. En general, la entrada del colectivo femenino en el mercado de trabajo remunerado no significa la distribución de las tareas domésticas entre los miembros de la familia. Con frecuencia se alivia esta sobrecarga cuando el nivel adquisitivo familiar permite la contratación de una asalariada que colabore en el cuidado del hogar.

Sin embargo, aún teniendo en cuenta la poco halagüeña situación laboral de las mujeres, cabría preguntarse cómo percibe el varón la intromisión de ésta en un espacio que podrían considerar como suyo. Sobre este particular resultan interesantes las conclusiones del trabajo de Martín y Gómez (1996) quienes ofrece algunas reacciones de los varones acerca de la inserción laboral de la mujer:

Toleran que salga del espacio doméstico para contribuir a la economía familiar siempre y cuando no asuma el papel protagonista ni supere sus cotas de éxito profesional.

- $\quad$ Siguen considerando el hogar como un espacio propio de la mujer en el que ellos están dispuestos a "ayudar".

- Cuando una pareja comparte los mismo espacios de trabajo y al mismo nivel, su opinión respecto de la relación es estar abocada al fracaso.

Completa esta visión, las tipologías de mujeres que se desprenden del discurso masculino, según los datos del trabajo realizado por los citados autores. En concreto diferencian tres categorías femeninas:

a) La mujer madre no trabajadora: es un referente importante ya que encarna el prototipo de mujer.

b) La mujer madre que trabaja para ayudar al marido: son mujeres no promocionables, "las que no llegan". Pese a ser válidas profesionalmente, se autoelimitan porque conceden prioridad a los hijos o al hogar. Abandonan su carrera o no se dedican lo que debieran al trabajo. Son vistas como trabajadoras mediocres y se las presenta como culpables de su escasa promoción.

c) La mujer promocionable: según el discurso de los varones "aparecen siempre como carentes": de hijos, de compañero sentimental; son mujeres solas, sin nadie que las quiera o de quién cuidar. Son las "solteras", "divorciadas", "viudas", "feas". ....; en síntesis, las fracasadas emocionalmente que subliman su carencia con el trabajo... Se las percibe "virilizadas": son especímenes raros que irrumpen en el espacio masculino (laboral), en el que son mal recibidos. 
Todo ello evidencia la escasa aceptación por parte del colectivo masculino de la mujer como profesional de éxito y su tendencia a mantener la situación de dominio sobre ella, tanto dentro de la familia como en el ámbito público. Pero aún hay más, con bastante frecuencia vemos como el desarrollo profesional de la mujer se supedita y se ve condicionado por el de su compañero, de tal forma que sus elecciones han de ser útiles para la promoción de la carrera del cónyuge (Langevin, 1995).

Este tipo de opiniones, sin ser afortunadamente generalizables, revela la tendencia de algunos varones a considerar el trabajo remunerado como algo propio de su género, al que permiten acceder a la mujer más como alarde de generosidad que como un derecho. Es más, como es sabido, en momentos de crisis económica o cuando se incrementa la población parada, se aboga desde posturas tradicionales no sólo defendidas por hombres, por el regreso de las mujeres al ámbito doméstico para así liberar puestos de trabajo. Una vez más vemos como la integración de la mujer en la sociedad, como persona de pleno derecho, se encuentra a la mitad de un camino sinuoso y con obstáculos. Pero la barrera de mayor poder para lograr la igualdad de oportunidades entre géneros es la permanencia de una mentalidad colectiva trasnochada que tradicionalmente ha relegado al sector femenino a papeles sociales considerados como secundarios.

Por lo que respecta a la relación entre el género y la cualificación profesional, hemos de considerar que la pertenencia a un sexo determinado implica el desarrollo de ciertas conductas y funciones que se caracterizarían por ser femeninas o masculinas bajo considerandos de tipo social. Estos roles que la sociedad otorga a los distintos sexos es lo que determina las diferencias de género.

El desarrollo profesional está mediatizado por las funciones asignadas al propio sexo. A nadie se le escapan las atribuciones en función del género de que han sido objeto de determinadas carreras profesionales. En ciertos momentos ha sido impensable la existencia de mujeres mineras, camioneras, ... o de hombres empleados en el servicio doméstico para la limpieza o cuidado de niños, matronas, etc. De esta forma, la elección de cada persona respecto de sus intereses profesionales va a estar condicionada por las tendencias de pensamiento social acerca de las profesiones adecuada o inadecuadas desde las perspectiva de género (Langevin, 1995).

La elección de estudios para la cualificación profesional no es ajena a los roles de género establecidos. A nivel nacional como internacional múltiples estudios reseñan las diferencias de opciones entre los sexos en la elección de su futura profesión (Sutherland, 1991; Müller, 1995; Muñoz, 1996, Torrens, 1996; etc.).

Por lo que respecta a la elección de estudios universitarios, la tendencia a nivel mundial es que mayoritariamente las estudiantes prefieren acceder a aquellas titulaciones catalogadas como "blandas", esto es, más cortas y de las ramas de Humanidades, Ciencias Sociales y Ciencias de la Salud, mientras que sus colegas masculinos cursan carreras "duras", tanto por su duración como por ser titulaciones incluidas en el bloque de la Ciencia y la Tecnología (Müller, 1995). Investigaciones llevadas a cabo en distintas universidades de nuestro país corroboran lo señalado, de modo que la mayor presencia femenina se concentra en determinadas carreras.

Otro matiz que diferencia el comportamiento entre los estudiantes y las estudiantes en la opción profesional que escogen, se centra en las posibilidades que ofrece de promoción o accesos a puesto de trabajo más elevados. Este aspecto resulta fundamental para los varones, quienes prefieren cursar titulaciones con techo profesional ilimitado; de ahí puede deducirse sus inclinaciones hacia estudios de tipo técnico y/o de aquellos asociados a profesiones liberales. 
También la remuneración económica previsible suele ser un acicate hacia la cualificación en determinadas ramas laborales. Así se explica el rechazo de un alto porcentaje del colectivo masculino hacia las carreras de letras, fundamentalmente cursadas por las mujeres.

En consecuencia, aún no disponiendo de datos concretos acerca de las carreras específicas realizadas por el alumnado universitario, parece comprobarse, en función de la revisión efectuada, las afirmaciones sobre las asimetrías de profesionalización entre los sexos ya mencionadas. Asimetría también constatada fuera de nuestra fronteras (Müller, 1995; Sutherland, 1991).

De hecho, como resultado de la inclinación hacia determinados estudios en función de los roles sociales atribuidos a los sexos, en nuestro país el empleo femenino se halla más concentrado que el masculino, de forma que más del $50 \%$ de la mujeres están empleadas en sólo cuatro ramas del sector servicios: comercio, sanidad y servicios sociales, educación e investigación y servicios personales. Sin embargo, la ocupación laboral de los hombres se halla mucho más dispersa, de forma que para acoger el $75 \%$ de esta población se requieren, nada menos que 10 ramas profesionales. Junto a esto y de cara a conseguir la igualdad de oportunidades en el empleo, es importante conocer que a nivel mundial los hombres tienden a conseguir mejores trabajos que las mujeres con los mismos años de educación (UNIFEM, 2000).

La especial disponibilidad del colectivo femenino hacia la atención y cuidado de los demás, junto a su papel de madre, puesta de manifiesto por sus inclinaciones profesionales, la ha hecho especialmente idónea, a ojos de la sociedad, para el ejercicio de actividades docentes. Habitualmente se ha considerado compatible el rol de la maternidad de la mujer con el hecho de ser educadora. De alguna manera se considera que el hecho de ser mujer, y por ende la posibilidad de ser madre, la dota de cualidades naturales para desempeñar el papel de educadora, como trabajo remunerado y en el seno familiar. Es por ello que una de las principales formas de acceso de la mujer al mundo laboral, a la esfera de lo público, ha sido como profesional de la educación (Langevin, 1995).

Algunas publicaciones reseñan diferencias entre géneros en el desempeño de la docencia en función de los niveles de enseñanza (Benítez et al. 1998); de modo que el avance hacia la enseñanza superior parece suponer la disminución de la participación docente de la mujer. Aunque se ha observado un alto índice de profesorado femenino en los niveles de enseñanza no universitaria, esta presencia se reduce en la enseñanza superior. Así, a principios de los noventa se constataba la superioridad de las docentes en la Educación Infantil (84\%), en Educación Primaria $(61 \%)$ y en Bachillerato (54\%), reduciéndose drásticamente su representación en la Universidad hasta un 29\%. (INE, 1993; Almarcha et al., 1994).

La igualdad en el acceso entre estudiantes de ambos sexos a la enseñanza superior, ya mencionada, debía haber subsanado el desequilibrio en el profesorado universitario, por ello nos inclinamos más a considerar otros factores como el dominio masculino o la influencia social negativa para la incorporación de la mujer al trabajo. Aún hoy, quedan secuelas de la mentalidad colectiva desde la que se consideraba innecesaria la cualificación profesional de la mujer a nivel superior, y en el mejor de los casos, se favorecía la realización de estudios de ciclo corto. Si además tenemos en cuenta la consideración de la mujer como "cuidadora y educadora por naturaleza" su ocupación fundamental se corresponde con la docencia en los niveles iniciales de la enseñanza.

Recapitulando, podemos afirmar que en la actualidad se observa:

La igualdad de género en el acceso a estudios universitarios. 
- $\quad$ La desigual opción en la elección profesional entre los estudiantes y las estudiantes como consecuencias de los condicionantes sociales.

- La desigual distribución del profesorado en los niveles de nuestro Sistema Educativo.

La solución a los problemas de desigualdad supone cambios importantes en todas las enseñanzas no universitarias, especialmente en la Educación Secundaria. En este sentido, se ha de tener especial cuidado en la eliminación de los estereotipos de género que tan frecuentemente aparecen en los contenidos educativos. También se ha de hacer especial hincapié en la intervención educativa dirigida a la construcción de valores que resalten la contribución de hombres y mujeres en el desarrollo social, económico y cultural y, por consiguiente, sus posibilidades de participación en todos los ámbitos de la vida. Tampoco conviene olvidar el papel trascendente que supone la orientación psicopedagógica para el futuro profesional y laboral de los estudiantes. Contar con una correcta información y asesoría en la elección de los estudios profesionalizadores, desde una perspectiva libre de estereotipos y cargas negativas hacia los géneros, será un excelente garante de posibilidades de cambios sociales hacia la igualdad de oportunidades entre las personas. Con idéntica finalidad será imprescindible incidir, desde el contexto educativo y social, en la familia, mediante estrategias que faciliten el cambio de mentalidad y promuevan patrones de comportamientos menos encasillados por tópicos de género (Programas de educación de padres, difusión de información en medios de comunicación, ....).

Si todo lo mencionado es necesario, resulta inexcusable la adopción de medidas políticas de la igualdad de oportunidades como fin primordial para el equilibrio social, cultural y económico de los países. Máxime cuando se ha demostrado la correlación existente entre el progreso económico de las naciones y la equidad de géneros (UNIFEM, 2000).

Conscientes de la desigualdad de trato y de oportunidades entre hombres y mujeres, desde hace unos años distintos gobiernos de la comunidad internacional, y en concreto de la Unión Europea, han puesto en marcha acciones centradas en la igualdad de trato, en el mainstreaming y en medidas de acción positiva dirigidas hacia la mujer. Estas estrategias, que quedan bien escritas en los documentos oficiales, requieren de esfuerzos máximos para su aplicación en la realidad; de lo contrario todo quedará en pliegos de buenas intenciones, como sucede con frecuencia.

Todo lo comentado, hace vislumbrar la existencia de ciertas transformaciones en la mentalidad social, pero aún queda mucho camino para eliminar una serie de prejuicios socialmente avalados que en nada favorecen al crecimiento de los individuos como personas, independientemente de su género. En ciertos momentos, parecía que el acceso a la educación superior era la vía de conseguir la igualdad entre hombres y mujeres en todos los ámbitos de la vida (privado y público); hoy por hoy, pese a que la formación universitaria es una realidad para la mayoría de la población, la equidad, el equilibrio y la colaboración entre unos y otras aún no se ha conseguido en su totalidad.

\section{La evolución de la Institución Universitaria Española desde la perspectiva de género}

Como se recoge en algunos estudios, el porcentaje de profesoras universitarias en los últimos años del franquismo era bastante bajo, ya que la mujer en la enseñanza universitaria sólo alcanzaba el 18,43\% en el curso académico 1975-76. Esta escasa representatividad era consecuencia de condicionantes políticos y de la rigidez de las estructuras, tanto universitarias como políticas y sociales de la época. 
La democracia, al traer consigo la flexibilización de la política, la promulgación de la Constitución y la apertura a corrientes socioculturales de otras naciones, da lugar al cambio de pensamientos con respecto a la población femenina. Progresivamente se deja de considerar que la finalidad vital de la mujer es la crianza y educación de los hijos y la atención del marido, para otorgarle la categoría de persona con todos los derechos. Esto explica la incorporación masiva de la mujer a la educación y, más específicamente, a los estudios universitarios.

Este cúmulo de circunstancias dan como resultado el aumento de la participación femenina en la enseñanza universitaria; de modo que del $18,4 \%$ de $1975-76$ se pasa aproximadamente al $21 \%$ en $1985-86$ y al $29 \%$ correspondiente al curso académico 1989-90. Todo ello supone una evolución muy importante de su presencia en las instituciones académicas en relación con la época anterior, aunque insignificante si se compara con el número total de docentes varones.

Para ver la evolución que han seguido las universidades españolas en la contratación de profesorado durante la última década, hemos comparado los datos correspondiente a los cursos académicos que se incluyen entre 1990-91 y 1999-2000, seleccionando aquellos entre los que media un intervalo temporal de dos años, y recogiendo como punto de contraste las cifras correspondientes al curso 1985-86.

Tabla 1

Evolución del profesorado entre 1975 y 1990

\begin{tabular}{|c|c|c|c|c|c|}
\hline $\begin{array}{c}\text { Años } \\
\text { académicos }\end{array}$ & Profesorado & $\begin{array}{c}\mathbf{N}^{\circ} \\
\text { Profesoras }\end{array}$ & $\begin{array}{c}\% \\
\text { Profesoras }\end{array}$ & $\begin{array}{c}\mathbf{N}^{\circ} \\
\text { Profesores }\end{array}$ & $\begin{array}{c}\% \\
\text { Profesores }\end{array}$ \\
\hline $1975-76$ & 30.876 & 5.702 & 18,47 & 25.174 & 81.53 \\
\hline $1980-81$ & 40.384 & 8.595 & 21,30 & 31.789 & 78.70 \\
\hline $1985-86$ & 45.259 & 11.345 & 25,07 & 33.914 & 74,93 \\
\hline $1989-90$ & 56.917 & 16.530 & 29,04 & 40.387 & 70,96 \\
\hline
\end{tabular}

Fuentes: INE. Estadéstica de la Enseñanza en España. Cursos1975-76 a 1989-90. Elaboración propia.

Tabla 2

Evolución del profesorado por sexo en los años 90

\begin{tabular}{|c|c|c|c|c|c|}
\hline $\begin{array}{c}\text { Años } \\
\text { académicos }\end{array}$ & N & Profesoras & $\begin{array}{c}\% \\
\text { Profesoras }\end{array}$ & Profesores & $\begin{array}{c}\% \\
\text { Profesores }\end{array}$ \\
\hline $1985-86$ & 45.259 & 11.345 & 25,07 & 33.914 & 74,93 \\
\hline $1990-91$ & 63.665 & 18.644 & 29,28 & 45.021 & 70,72 \\
\hline $1995-96$ & 82.951 & 26.580 & 32,04 & 56.371 & 67,96 \\
\hline $1999-2000$ & 99.619 & 34.119 & 34,25 & 65.500 & 65,75 \\
\hline
\end{tabular}

Fuentes: INE. Estadéstica de la Enseñanza Superior en España. Elaboración propia. 
A primera vista, igual que en el periodo anterior, se constata una progresión ascendente y bastante regular de las cifras totales del profesorado universitario. Sin embargo, el crecimiento mayor se produce en la primera mitad de los noventa. El análisis de las cifras totales de docentes por sexo muestra una tendencia muy similar entre ambos colectivos a lo largo del tiempo. Aunque se evidencia un menor incremento en la contratación de profesoras que en la de sus colegas varones, no hemos encontrado entre los cursos observados, ni las oscilaciones ni los estancamientos en la evolución de las mujeres como docentes, a los que, por ejemplo, se refería Grañeras et al. (1999).

Por lo que respecta a la distribución del profesorado por categorías académicas, las cifras ponen de manifiesto el constante incremento de las plazas de profesores Asociados entre 1985 y el 2000 , de modo que de 8.675 en 1985, este colectivo se amplía a 28.729 en el 2000. También se observa una tendencia ascendente en el profesorado Titular de Universidad y de Escuela Universitaria, cuya cuantía al final de la década de los 90 es más del triple y el doble respectivamente. Si bien el mayor crecimiento en las dotaciones de Titulares de Universidad se sitúa en el periodo comprendido entre 1985 y 1990, posteriormente se produce

\section{Gráfico 1}

Evolución del profesorado por sexos

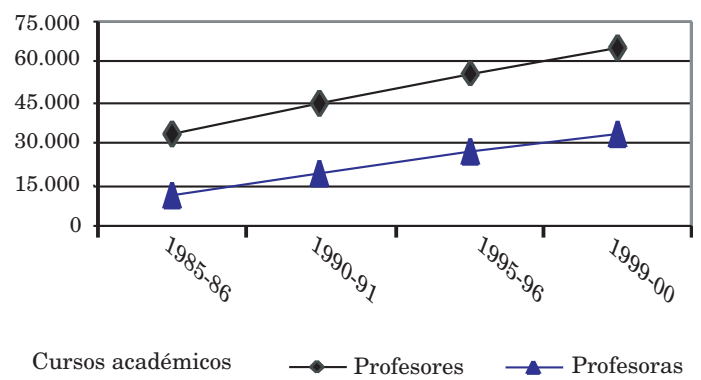

una progresión más reducida y con oscilaciones. Por su parte, el acceso a Titulares de Escuela Universitaria es más escalonado a lo largo del tiempo. Las Cátedras de Universidad se mantienen sin cambios llamativos, aunque se aprecian leves oscilaciones, mientras que las Ayudantías tienden a la reducción.

Para realizar el análisis de la situación y evolución de categorías académicas en función del sexo, hemos tomado como referente la información de una serie de años distanciados. De esta manera podemos comparar los indicadores de otros momentos con las dotaciones actualmente existentes para cada modalidad, a la vez que detectar cambios en las tendencias de ocupación de plazas.

La distribución del profesorado en los diversos niveles docentes de la enseñanza superior desde 1985-86 al año 2000, demuestra que su crecimiento es mayor en los profesores que en las profesoras. Ni tan siquiera en el sondeo de los cursos 95 y 99, más cercanos a la actualidad, se percibe modificación alguna que prediga un futuro de mayor equilibrio entre el profesorado de distinto sexo. Un tendencia semejante se constata en estudios recientes de otras universidades (Andino, 2001). Por tanto, profundizando en el reparto del profesorado por categorías, vemos a lo largo del tiempo que:

En las Cátedras de Universidad, la presencia de la mujer sigue siendo mínima y su crecimiento en cifras totales no supera el número de 300 Catedráticas en una década.

El profesorado Titular es uno de los colectivos más beneficiado en provisiones de plazas; en lo que al género se refiere, en los 90 existe una mayor proximidad entre los porcentajes del profesorado de ambos sexos, si bien el masculino mantiene su predominio en esta categoría. 
- En lo tocante a las categorías académicas de Escuelas Universitarias, tanto de Cátedra como de Titularidad, se evidencia a lo largo del tiempo una mayor proximidad entre géneros. Índices femeninos que se asocian con la tendencia tradicional de la mujer a estudiar carreras de ciclo corto, lo que ha posibilitado su mayor acceso profesional a la docencia en centros que imparten este tipo de estudios.

- $\quad$ En las modalidades docentes de carácter extraordinario, Asociado y Ayudante, los hombres superan la cifra de mujeres en los últimos años. Ello es especialmente notorio en los índices de plazas de Asociados, existiendo más igualdad en las de Ayudantes. En el resto de estratos académicos la presencia de las mujeres es aún menor, si cabe, que en las ya revisadas, propendiendo además a la baja; a excepción de la de profesorado Visitante.

En definitiva, estos datos no hacen más que corroborar los resultados de muchas de las investigaciones e informes que nos han precedido. Se observa la presencia mayoritaria de profesorado varón en todas las categorías, si bien éste es mayor cuanto más se asciende en la escala hacia niveles de mayor reconocimiento y prestigio. Esta estructura del profesorado presenta variaciones hacia un mayor equilibrio en áreas de conocimiento de nueva creación y en departamentos de facultades jóvenes donde los círculos de poder no están tan establecidos.

Tabla 3

Evolución personal docente por categorías académicas

\begin{tabular}{|c|c|c|c|c|c|c|c|c|}
\hline \multirow[b]{2}{*}{ Categorías docentes } & \multicolumn{2}{|c|}{ 1985-86 } & \multicolumn{2}{|c|}{ 1991-91 } & \multicolumn{2}{|c|}{$1995-96$} & \multicolumn{2}{|c|}{ 1999-00 } \\
\hline & $\mathbf{N}$ & $\%$ & $\mathbf{N}$ & $\%$ & $\mathbf{N}$ & $\%$ & $\mathbf{N}$ & $\%$ \\
\hline Catedrático/a y agregado/a & 3.864 & 8,99 & 5.287 & 8,77 & 6.365 & 9,14 & 7.373 & 9,24 \\
\hline Titular de Universidad & 9.801 & 22,81 & 18.827 & 31,22 & 19.635 & 28,18 & 23.605 & 29,59 \\
\hline Catedrático/a y agregado/a de E.U. & 2.036 & 4,74 & 1.709 & 2,83 & 1.660 & 2,38 & 1.994 & 2,5 \\
\hline Titular de Escuela Universitaria & 5.119 & 11,92 & 8.642 & 14,33 & 11.077 & 15,9 & 11.521 & 14,44 \\
\hline Encargado/a curso y Asociado/a & 8.675 & 20,19 & 17.310 & 28,7 & 24.329 & 34,92 & 28.729 & 36,01 \\
\hline Ayudante & 6.070 & 14,13 & 4.318 & 7,16 & 4.726 & 6,78 & 4.310 & 5,4 \\
\hline Emérito/a & - & 0 & 335 & 0,56 & 571 & 0,82 & 392 & 0,49 \\
\hline Maestro/a de taller & 1.137 & 2,65 & 455 & 0,75 & - & 0 & - & 0 \\
\hline Profesor visitante & - & 0 & 196 & 0,32 & 348 & 0,5 & 329 & 0,41 \\
\hline Otro Profesorado y no consta & 6.259 & 14,57 & 3.235 & 5,36 & 962 & 1,38 & 1.526 & 1,91 \\
\hline Total & 42.961 & 100 & 60.314 & 100 & 69.673 & 100 & 79.779 & 99,99 \\
\hline
\end{tabular}

Fuentes: Elaboración propia a partir de los datos del INE. Estadística de la Enseñanza. 
En estos ámbitos universitarios existe una menor discriminación del profesorado femenino (Cirujano, 2001). El análisis de la edad del profesorado parece abrir una perspectiva de futura igualdad en la institución universitaria. Sobre este aspecto los datos del Instituto Nacional de Estadística del curso 1999-00 revelan un mayor equilibrio entre el colectivo de profesorado más joven. Se haya paridad en las cifras de profesores de ambos sexos, en las edades comprendidas entre los 24 y los 34 años. Sin embargo a partir de esta edad la presencia de la mujer es inversamente proporcional.

Tabla 4

Distribución del profesorado por categorías académicas y sexo

\begin{tabular}{|l|c|c|c|c|c|c|c|c|c|c|}
\cline { 2 - 11 } & \multicolumn{2}{|c|}{ Curso académico 1985-1986 } & \multicolumn{3}{c|}{ Curso académico 1990-1991 } \\
\hline Categorías docentes & $\mathbf{N}$ & $\mathbf{H}$ & $\mathbf{\%}$ & $\mathbf{M}$ & $\mathbf{\%} \mathbf{M}$ & $\mathbf{N}$ & $\mathbf{H}$ & \% H & $\mathbf{M}$ & \% M \\
\hline Catedrático/a y agregado/a & 3.864 & 3.587 & 8,35 & 277 & 0,64 & 5.287 & 4.749 & 7,87 & 538 & 0,89 \\
\hline Titular de Universidad & 9.801 & 7.498 & 17,45 & 2.303 & 5,36 & 18.827 & 13.204 & 21,89 & 5.623 & 9,32 \\
\hline Catedrático/a y agregado/a de E.U. & 2.036 & 1.445 & 3,39 & 581 & 1,35 & 1.709 & 1.193 & 1,98 & 516 & 0,86 \\
\hline Titular de Escuela Universitaria & 5.119 & 3.301 & 7,68 & 1.818 & 4,23 & 8.642 & 5.382 & 8,92 & 3.260 & 5,41 \\
\hline Encargado/a curso y Asociado/a & 8.675 & 6.704 & 15,6 & 1.971 & 4,59 & 17.310 & 12.633 & 20,95 & 4.677 & 7,75 \\
\hline Ayudante & 6.070 & 3.085 & 8,86 & 2.265 & 5,27 & 4.318 & 2.277 & 3,78 & 2.041 & 3,38 \\
\hline Emérito/a & - & 0 & 0 & 0 & 0 & 335 & 320 & 0,53 & 15 & 0,02 \\
\hline Maestro/a de taller & 1.137 & 909 & 2,12 & 228 & 0,53 & 455 & 376 & 0,62 & 79 & 0,13 \\
\hline Profesor visitante & - & 0 & 0 & 0 & 0 & 196 & 147 & 0,24 & 49 & 0,08 \\
\hline Otro Profesorado y no consta & 6.259 & 4.053 & 9,43 & 2.206 & 5,13 & 3.235 & 2.170 & 3,6 & 1.065 & 1,77 \\
\hline Total & $\mathbf{4 2 . 9 6 1}$ & 31.312 & 72,88 & 11.649 & 27,12 & $\mathbf{6 0 . 3 1 4}$ & 42.451 & 70,38 & 17.863 & 29,62 \\
\hline
\end{tabular}


Tabla 5

Distribución del profesorado por categorías académicas y sexo (continuación)

\begin{tabular}{|c|c|c|c|c|c|c|c|c|c|c|}
\hline \multirow[b]{2}{*}{ Categorías docentes } & \multicolumn{5}{|c|}{ Curso académico 1995-1996 } & \multicolumn{5}{|c|}{ Curso académico 1999-2000 } \\
\hline & $\mathbf{N}$ & $\mathbf{H}$ & $\% \mathbf{H}$ & $\mathbf{M}$ & $\% \mathbf{M}$ & $\mathbf{N}$ & $\mathbf{H}$ & $\% \mathbf{H}$ & $\mathbf{M}$ & $\% \mathbf{M}$ \\
\hline Catedrático/a y agregado/a & 6.365 & 5.680 & 8,15 & 685 & 0,98 & 7.373 & 6.493 & 8,14 & 880 & 1,1 \\
\hline Titular de Universidad & 19.635 & 13.356 & 19,17 & 6.279 & 9,01 & 23.605 & 15.762 & 19,76 & 7.843 & 9,83 \\
\hline Catedrático/a y agregado/a de E.U. & 1.660 & 1.208 & 1,73 & 452 & 0,65 & 1.194 & 1.429 & 1,79 & 565 & 0,71 \\
\hline Titular de Escuela Universitaria & 11.077 & 6.736 & 9,67 & 4.341 & 6,23 & 11.521 & 6.861 & 8,6 & 4.660 & 5,84 \\
\hline Encargado/a curso y Asociado/a & 24.329 & 16.912 & 24,27 & 7.417 & 10,65 & 28.729 & 19.211 & 24,08 & 9.518 & 11,93 \\
\hline Ayudante & 4.726 & 2.584 & 3,71 & 2.142 & 3,07 & 4.310 & 2.290 & 2,87 & 2.020 & 2,53 \\
\hline Emérito/a & 571 & 468 & 0,67 & 103 & 0,15 & 392 & 338 & 0,42 & 54 & 0,07 \\
\hline Maestro/a de taller & - & 0 & 0 & 0 & 0 & - & 0 & 0 & 0 & 0 \\
\hline Profesor visitante & 348 & 272 & 0,39 & 76 & 0,11 & 329 & 212 & 0,27 & 117 & 0,15 \\
\hline Otro Profesorado y no consta & 962 & 748 & 1,07 & 214 & 0,31 & 1.526 & 902 & 1,13 & 624 & 0,78 \\
\hline at al & 6963 & 47.964 & 68,84 & 21.709 & 31,16 & 99 & 53.498 & 67,06 & 26.281 & 32,94 \\
\hline
\end{tabular}

Fientes:\$. Estad $\quad$ "stica de la Ense\#ana Gprior en Esp

\#a. Cursos:19951996 y 19992000. Elabraci \$n popa.

\section{La institución universitaria en la Comunidad Autónoma de Castilla y León}

En la actualidad las universidades públicas que configuran el panorama actual de Castilla y León son las de Burgos, León, Salamanca y Valladolid; estructuración universitaria que tiene su origen en 1994 con la creación de la Universidad de Burgos ${ }^{1}$.

En lo tocante a la evolución del profesorado, se observa un leve crecimiento a lo largo del lustro. En concreto, la variación numérica supone un ascenso de 506 docentes entre el primer y segundo periodo (199596 y 1997-98) y de 288 entre el segundo y el tercero (1997-98 y 1999-00), lo que corresponde a un $8,5 \%$ y un $4,6 \%$ de diferencia, respectivamente. Se demuestra así que el crecimiento del profesorado es aproximadamente el doble entre 1995 y 1997 que en el último espacio de tiempo.

Gráfico 2

Evolución del profesorado

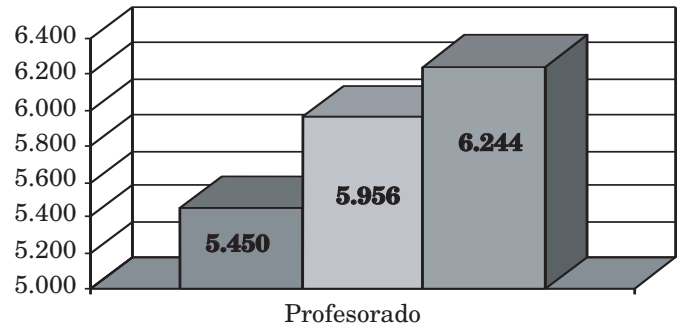

$\begin{array}{lll}\square 1995-96 & \square 1997-98 \quad \square 1999-00\end{array}$ 
La introducción de la variable sexo en relación al profesorado universitario pone de manifiesto la superioridad numérica del colectivo masculino frente al femenino a lo largo del tiempo contemplado. El examen de los valores absolutos demuestra el crecimiento de los profesores duran- te el quinquenio, cuya variación supone un $5,17 \%$ en el primer periodo y un $4,74 \%$ en el segundo. En cambio las docentes, aunque participan de la tendencia al alza del profesorado entre 1995 y 1997, reducen levemente su número en el curso 1999-00.

Tabla 6

Evolución del profesorado por sexo

\begin{tabular}{|c|c|c|c|c|c|c|}
\hline & \multicolumn{2}{|c|}{ Curso 1995-1996 } & \multicolumn{2}{c|}{ Curso 1997-1998 } & \multicolumn{2}{c|}{ Curso 1999-200 } \\
\hline & $\mathbf{N}$ & $\%$ & $\mathbf{N}$ & $\%$ & $\mathbf{N}$ & $\%$ \\
\hline Profesores & 3.519 & 64,57 & 3.827 & 64,25 & 4.123 & 66,03 \\
\hline Profesoras & 1.931 & 35,43 & 2.129 & 35,75 & 2.121 & 33,97 \\
\hline
\end{tabular}

La profundización en el estudio del profesorado de Castilla y León desde la perspectiva de género nos ha llevado a analizar también cuál es su reparto en las diversas universidades de la región. Los datos expuestos revelan mayor presencia femenina en las Universidades de Valladolid $(13,8 \%)$ y Salamanca $(12,8 \%)$, las cuales se distancian notablemente de las de Burgos (4\%) y la de León (4,7\%). Como posible motivo de esta diferencia entre universidades, en cuanto a su personal docente, podría aludirse a que tanto en la Universidad de Burgos como en la de León se imparten preferentemente Enseñanzas Técnicas, tradicionalmente masculinizadas. Asimismo, se aprecia que la disminución numérica de las profesoras en el último tramo temporal se origina en estas dos universidades.

Tabla 7

Distribución del profesorado por sexo, cursos académicos y universidades

\begin{tabular}{|c|c|c|c|c|c|c|c|c|c|c|c|c|}
\hline & \multicolumn{3}{|c|}{$\begin{array}{c}\text { Universidad } \\
\text { de Burgos }\end{array}$} & \multicolumn{3}{c|}{$\begin{array}{c}\text { Universidad } \\
\text { de León }\end{array}$} & \multicolumn{3}{c|}{$\begin{array}{c}\text { Universidad } \\
\text { de Salamanca }\end{array}$} & \multicolumn{3}{c|}{$\begin{array}{c}\text { Universidad Valladolid } \\
\text { de Vada }\end{array}$} \\
\cline { 2 - 14 } & $\mathbf{N}$ & Mujeres & $\begin{array}{c}\text { \% } \\
\text { Mujeres }\end{array}$ & $\mathbf{N}$ & Mujeres & $\begin{array}{c}\% \\
\text { Mujeres }\end{array}$ & $\mathbf{N}$ & Mujeres & $\begin{array}{c}\% \\
\text { Mujeres }\end{array}$ & N & Mujeres & $\begin{array}{c}\% \\
\text { Mujeres }\end{array}$ \\
\hline $\mathbf{1 9 9 5 - 9 6}$ & 510 & 220 & 4,04 & 739 & 257 & 4,72 & 2.007 & 700 & 12,84 & 2.194 & 754 & 13,83 \\
\hline $\mathbf{1 9 9 7 - 9 8}$ & 684 & 234 & 3,93 & 809 & 288 & 4,84 & 2.036 & 737 & 12,37 & 2.427 & 870 & 14,61 \\
\hline $\mathbf{1 9 9 9 - 0 0}$ & 634 & 193 & 3,09 & 812 & 273 & 4,37 & 2.353 & 818 & 13,1 & 2.445 & 837 & 13,4 \\
\hline
\end{tabular}

Fuentes: INE. Estadéstica de la Enseñanza Superior en España. Cursos: 1995-1996; 1997-1998 y 1999-2000. Elaboración propia. 
En lo que respecta a la evolución de los profesores y profesoras en el acceso a puestos académicos, puede apreciarse como, durante el periodo analizado, la categoría profesional más frecuente entre el personal docente es la de Asociado, tal y como vimos también en el análisis efectuado a nivel nacional, hallándose menor índice en el colectivo femenino que en el masculino. Este dato puede resultar de interés si tenemos en cuenta que esta figura contractual está pensada en el contexto universitario español, para aquellos profesionales que tienen su puesto de trabajo fuera de la universidad, y que desean dedicar unas horas a la actividad docente, aportando su experiencia. La dificultad que manifiestan muchas profesionales a la hora de compatibilizar la vida familiar y laboral, corroborada en distintos estudios en torno al tema, puede ser la razón de que éstas no opten por desempeñar otra actividad complementaria a la que desarrollan prioritariamente, que pueda contribuir a mermar su tiempo de dedicación a actividades domésticas y familiares. Este incremento del profesorado Asociado contrasta con la escasa presencia de profesorado Ayudante, cuyas cifras se van reduciendo paulatina e independientemente del género de los profesores.

En lo tocante a las categorías de Catedráticos y Profesores Titulares de Universidad se pone de manifiesto una distribución desigual entre sexos, más acusada a favor de los hombres en las Cátedras, donde la presencia femenina sigue siendo puramente testimonial. Desequilibrio que también se evidencia en las Cátedras de Escuelas Universitarias; aunque sin duda, donde se halla una mayor proximidad entre sexos es en la provisión de Titularidades de Escuelas Universitarias.

En definitiva, el personal docente de las universidades de Castilla y León participa, en general, durante el periodo analizado, de la tendencia descrita en relación a la Universidad Pública del Estado Español. Esto supone el dominio masculino en todos los rangos académicos, aunque, como se ha podido observar, se va detectando una progresión positiva respecto de la presencia de la mujer.

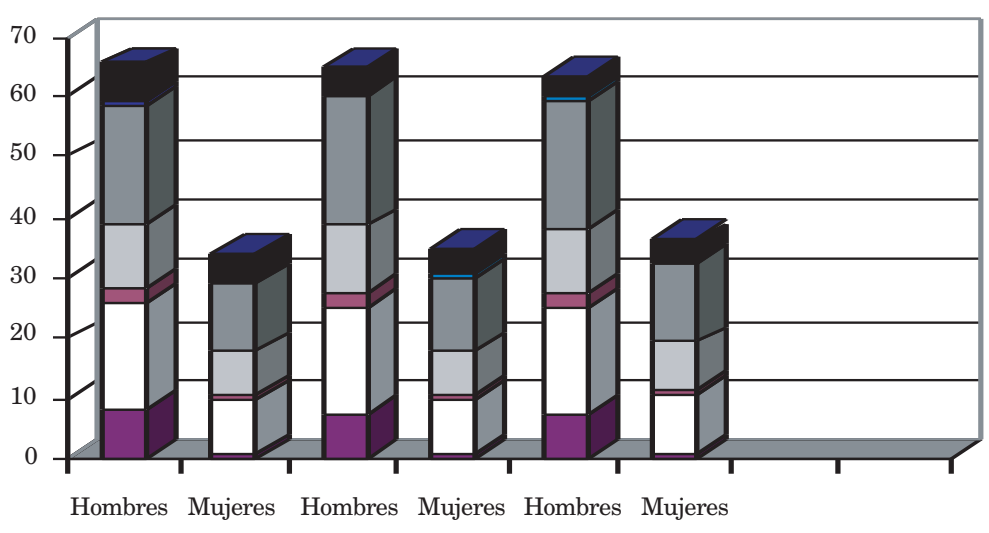

$1995-96$
$1997-98$
Otros/as y no consta

Prof/as. Ayudantes

Profesores/as visitantes

Prof. Eméritos/as

Profesores Asociados/as

Prof. Titular Esc. Univ.

Catedrñticos Esc. Univ.

$\square$ Prof. Titulares Univ.

Catedrñticos/as 


\section{Descripción de la investigación desarrollada}

Como comentamos inicialmente, el estudio que hemos llevado a cabo pretende analizar la institución universitaria de Castilla y León y, más concretamente, su personal docente desde la perspectiva de género. Ha sido nuestro interés explicitar las posibles dificultades a las que se enfrentan las académicas, tanto en el acceso a puestos docentes universitarios, como en el desempeño de las tareas profesionales y cargos de mayor responsabilidad. Asimismo nos parecía oportuno conocer también cómo perciben las propias profesionales estas dificultades y sus actitudes al respecto. De acuerdo con estas inquietudes, los objetivos que han guiado el trabajo de investigación han sido los siguientes:

1. Estudiar la posible relación entre género y acceso a puestos docentes universitarios.

2. Conocer cómo es percibida la relación género/acceso a puestos docentes, por el profesorado de las Universidades de Castilla y León.

3. Determinar la posible influencia que puede tener la pertenencia a un ámbito de conocimiento tradicionalmente masculinizado (por ej. Ciencias), en las posibilidades de acceso a puestos docentes en la Universidad.

4. Detectar si existen posibles diferencias de género para acceder a cargos de mayor responsabilidad (directivos, de gestión, etc.) y a las categorías profesionales superiores (Catedráticos).

Con el fin de que el personal docente e investigador de las Universidades Públicas de Castilla y León pudiera manifestar su opinión al respecto, el equipo de investigación ${ }^{2}$ elaboró un cuestionario con dos partes claramente diferenciadas: La primera orientada a efectuar una caracterización personal y profesional de los docentes universitarios de Castilla y León desde la perspectiva de género (datos de identificación y clasificación de la muestra, y cuestiones relativas a la formación académica, perfil profesional, actividad docente y cargos de dirección y gestión del profesorado). La segunda incluyó una serie de cuestiones orientadas a recoger información sobre responsabilidades familiares y domésticas, la percepción que profesores y profesoras tienen de las mismas, y su implicación en el rendimiento profesional, en las aspiraciones, motivación y satisfacción laboral de los docentes.

La relación de variables consideradas en la elaboración de este cuestionario son las que detallamos seguidamente: 


\section{Cuadro 1}

Relación de variables consideradas en la investigación

\begin{tabular}{|c|}
\hline $\begin{array}{l}\text { Variables personales } \\
\text { Sexo, Edad, Estado Civil, Trabajo de la pareja fuera de casa, Número de hijos }\end{array}$ \\
\hline $\begin{array}{l}\text { Variables académicas } \\
\text { Universidad en la que finaliza sus estudios, Titulación de mayor rango académico, } \\
\text { Tiempo invertido en la Tesis Doctoral }\end{array}$ \\
\hline $\begin{array}{l}\text { Variables profesionales } \\
\text { Universidad y Centro en el que trabaja, Años de docencia Universitaria, Trabajo en otras universidades } \\
\text { y desempeño de otras actividades profesionales, Categorías profesionales por las que han pasado los } \\
\text { docentes, Tiempo de docencia ejercido como profesor no numerario, Número de tramos obtenidos } \\
\text { de docencia e investigación, Aspiración a concluir la carrera docente como Catedrático }\end{array}$ \\
\hline $\begin{array}{c}\text { Variables docentes } \\
\text { Asignaturas impartidas, Número de créditos, Participación en Programas de Doctorado } \\
\text { y Cursos de Postgrado }\end{array}$ \\
\hline $\begin{array}{l}\text { Variables de dirección y gestión } \\
\text { Interés y capacidad para desempeñar cargos de dirección y gestión, Participación } \\
\text { en Órganos Unipersonales y Colegiados, Cargos de dirección o coordinación de otras } \\
\text { actividades docentes (Doctorado, Máster, Cursos de Postgrado, Comisiones, Congresos) }\end{array}$ \\
\hline $\begin{array}{l}\text { Variables de percepción sobre igualdad entre géneros } \\
\text { Trato profesional, Acceso a puestos docentes y cargos de representación, Mujeres } \\
\text { que ocupan puestos de responsabilidad, Ventajas del género en la función docente, } \\
\text { Preferencias en la configuración de equipos de investigación }\end{array}$ \\
\hline $\begin{array}{l}\text { Variables familiares } \\
\text { Personas a su cargo, Atención y cuidado de los miembros de la familia, Tareas domésticas } \\
\text { y familiares realizadas habitualmente, Ayuda externa y familiar para las actividades } \\
\text { domésticas, Esfuerzo de las tareas profesionales y personales }\end{array}$ \\
\hline $\begin{array}{l}\text { Variables de rendimiento } \\
\text { Rendimiento profesional, producción científica }\end{array}$ \\
\hline $\begin{array}{c}\text { Variables sobre desigualdad de género en el ámbito universitario } \\
\text { Disponibilidad para asistir a reuniones de trabajo, Accesibilidad a los alumnos, Preferencia } \\
\text { para obtener plaza, accesibilidad a puestos de poder }\end{array}$ \\
\hline
\end{tabular}

Tomando como criterio los objetivos propuestos en esta investigación, se definió la población objeto de estudio, como el conjunto del profesorado universitario que pertenece a las universidades públicas de Castilla y León. En el curso académico 1999/2000 esta población ascendía a un total de 5.816 docentes, de los que 2113 (37\%) eran mujeres y 3703 (63\%) hombres. El cuestionario se envió por correo ordinario a los profesores de las cuatro universidades Castellano Leonesas, recogiéndose un total de 901, que representan el 15,49\% del total del profesorado. De éstos, 489 fueron de hombres $(54,9 \%)$ y 402 de mujeres $(45,1 \%)$.

Los datos obtenidos mediante el cuestionario se completaron con la información procedente de un grupo de discusión, 
organizado con la intención de conocer el discurso de las profesoras y profesores universitarios sobre la relación entre género y función docente.

Finalizado el trabajo de campo se realizó el procesamiento de la información recogida. Primero se preparó el registro de codificación y, posteriormente, se procesaron los 901 cuestionarios recogidos en un fichero elaborado "ad hoc". Una vez creado el fichero e introducidos los datos procedimos a la depuración de los mismos, y a la realización de los análisis de carácter descriptivo y correlacional, con ayuda del programa estadístico SPSS 10.0.

De forma más concreta, los análisis estadísticos realizados con el fichero elaborado ad hoc fueron los siguientes:

- Un estudio descriptivo de la muestra (Global y por Segmentos Muestrales)

- Un estudio comparativo e inferencial (pruebas de significación)

- Un estudio de relaciones entre variables (Coeficientes de correlación)

Las pruebas estadísticas con las qué contrastar la hipótesis nula que se han utilizado en esta investigación han sido: prueba de significación de diferencia de medias en muestras independientes, análisis de varianza y "chi" cuadrado.

En este artículo vamos a presentar los principales resultados obtenidos en la primera parte del cuestionario que, tal como ya señalamos, se centró en obtener información que nos permitiese caracterizar a los docentes universitarios de Castilla y León desde una perspectiva de género, a partir de las siguientes variables: personales, académicas, profesionales, docentes, de dirección y gestión. Los resultados obtenidos en la segunda parte del cuestionario han sido objeto de otra publicación.

\section{Resultados}

\subsection{Datos personales del profesorado}

- Sexo, edad y estado civil

La mayor parte del profesorado que constituye la muestra (71,9 \% de los hombres y un $81 \%$ de las mujeres) tiene edades comprendidas entre los 30 y 50 años, están casados o comparten su vida en pareja $(69,3 \%)$, siendo escaso el porcentaje de docentes separado-divorciado o viudo.

Los análisis efectuados ponen de manifiesto que hay más profesores casados o compartiendo su vida en pareja, que profesoras. Se trata de un dato ya confirmado en algunas investigaciones anteriores (Barbera, Lafuente y Sarrió, 1998), en las que se constatan diferencias entre profesorado de uno y otro sexo, en cuanto a la situación familiar. Concretamente, los datos aportados en estos trabajos señalan que las profesoras conviven en pareja en una proporción significativamente menor que los hombres, tienen menos hijos o deciden no tenerlos, dato éste último que también se constata en nuestro estudio, tal y como se podrá apreciar posteriormente. Creemos que la percepción, por parte de las profesoras, de la existencia de una incompatibilidad entre la familia y el desarrollo de la carrera profesional, puede ser, entre otros, uno de los motivos que explique esta tendencia.

\section{- Hijos}

Más de la mitad de los docentes encuestados tiene hijos $(60,2 \%), 1$ ó 2 por lo general $(44,5 \%)$.

El sexo del profesorado parece ser una variable que influye en el hecho de tener o no hijos y en el número de los mismos, de modo que, tal como se observa en las siguientes tablas, son los profesores varones quienes en mayor medida responden afirmativamente cuando se les pregunta si tienen hijos $(p=0,001) y$, los que a su vez, manifiestan tener más $(p=0,015)$. 
Tabla 8

Sexo, edad y estado civil del profesorado

\begin{tabular}{|c|c|c|c|c|c|c|c|}
\hline & & \multicolumn{2}{|c|}{ Total } & \multicolumn{2}{|c|}{ Hombres } & \multicolumn{2}{|c|}{ Mujeres } \\
\hline & & $\mathbf{N}$ & $\%$ & $\mathbf{N}$ & $\%$ & $\mathbf{N}$ & $\%$ \\
\hline \multicolumn{2}{|c|}{ Sexo } & 901 & 100 & 489 & 54,9 & 402 & 45,1 \\
\hline \multirow{6}{*}{ Edad } & Menos de 30 años & 66 & 7,4 & 30 & 6,2 & 33 & 8,3 \\
\hline & 30-40 años & 431 & 48,8 & 217 & 44,7 & 214 & 54 \\
\hline & 41-50 años & 241 & 27,1 & 132 & 27,2 & 107 & 27 \\
\hline & 51-60 años & 130 & 14,6 & 86 & 17,7 & 41 & 10,4 \\
\hline & Mas de 60 años & 22 & 2,5 & 20 & 4,1 & 1 & 0,3 \\
\hline & No contesta & 3 & 0,3 & 2 & 0,4 & 1 & 0,2 \\
\hline \multirow{5}{*}{ Estado civil } & Soltero/a & 237 & 26,3 & 112 & 23 & 124 & 30,8 \\
\hline & Casado/a - pareja de hecho & 624 & 69,3 & 361 & 74 & 256 & 63,7 \\
\hline & Separado/a - Divorciado/a & 32 & 3,6 & 14 & 2,9 & 18 & 4,5 \\
\hline & Viudo/a & 5 & 0,6 & 1 & 0,2 & 4 & 1 \\
\hline & No contesta & 1 & 0,1 & 1 & 0,2 & 0 & 0 \\
\hline
\end{tabular}

Tabla 9

Hijos y sexo

\begin{tabular}{|c|c|c|c|}
\hline & & \multicolumn{2}{|c|}{ Sexo } \\
\hline & & Hombre & Mujer \\
\hline \multirow{2}{*}{ Hijos } & $\mathbf{S i}$ & $35,9 \%$ & $24 \%$ \\
\hline & No & $19,5 \%$ & $20,6 \%$ \\
\hline \multicolumn{2}{|c|}{ N Total } & \multicolumn{2}{|c|}{838} \\
\hline \multicolumn{2}{|c|}{ Chi-cuadrado $=10,675$} & \multicolumn{2}{|c|}{$p=0,001$} \\
\hline
\end{tabular}


Tabla 10

Número de hijos

\begin{tabular}{|c|c|c|c|c|}
\cline { 2 - 5 } \multicolumn{1}{c|}{} & \multicolumn{2}{|c|}{ Medias } & \multicolumn{2}{c|}{ Prueba T } \\
\cline { 2 - 5 } & $\mathbf{H}$ & $\mathbf{M}$ & $\mathbf{t}$ & $\mathbf{p}^{*}$ \\
\hline $\mathbf{N}^{\circ}$ de hijos & 2,06 & 1,85 & 2,445 & 0,015 \\
\hline
\end{tabular}

* Los valores menores a 0,05 pueden considerarse estadísticamente significativos.

\subsection{Formación académica}

- Universidad en la que se finalizaron estudios y titulación de mayor rango académico

La mayoría del profesorado finalizó sus estudios en la Universidad de Salamanca
$(33,8 \%)$ o de Valladolid $(24,3 \%)$ y la titulación que posee una proporción importante de ellos es la de Doctor $(67,1 \%)$, seguida de la de Licenciado $(28,7 \%)$, siendo más frecuente la primera entre los profesores varones $(p=0,02)$.

Tabla 11

Universidad en la que estudío el profesorado y titulación de mayor rango

\begin{tabular}{|c|c|c|c|c|c|c|c|}
\hline & & \\
\hline & & \multicolumn{2}{|c|}{ Tt al } & \multicolumn{2}{|c|}{ o Embres } & \multicolumn{2}{|c|}{ Mjeres } \\
\hline & & $\mathbf{N}$ & $\%$ & $\mathbf{N}$ & $\%$ & $\mathbf{N}$ & $\%$ \\
\hline \multirow{8}{*}{$\begin{array}{l}\text { hiversidad } \\
\text { en la que se } \\
\text { finalizaron } \\
\text { estudios }\end{array}$} & Burgos & 14 & 1,6 & 10 & 2 & 4 & 1 \\
\hline & León & 64 & 7,2 & 34 & 7 & 30 & 7,5 \\
\hline & Pontificia Salamanca & 21 & 2,4 & 9 & 1,8 & 12 & 3 \\
\hline & Salamanca & 302 & 33,8 & 165 & 33,7 & 133 & 33,3 \\
\hline & M ladolid & 217 & 24,3 & 109 & 22,3 & 106 & 26,6 \\
\hline & Otra espa " ola & 237 & 26,5 & 138 & 28,2 & 96 & 24,1 \\
\hline & Otras & 38 & 4,3 & 20 & 4,1 & 18 & 4,5 \\
\hline & No contesta & 6 & 0,7 & 4 & 0,8 & 2 & 0,5 \\
\hline \multirow{4}{*}{$\begin{array}{l}\text { ulación de } \\
\text { mayor rango } \\
\text { acad ! mico }\end{array}$} & Plomado & 38 & 4,3 & 21 & 4,3 & 16 & 4 \\
\hline & Licenciado & 256 & 28,7 & 120 & 24,5 & 133 & 33,1 \\
\hline & Detor & 599 & 67,1 & 342 & 69,9 & 252 & 62,7 \\
\hline & No contesta & 7 & 0,8 & 6 & 1,2 & 1 & 0,2 \\
\hline
\end{tabular}


Tabla 12

Titulación de mayor rango académico y sexo

\begin{tabular}{|c|l|c|c|}
\cline { 3 - 4 } \multicolumn{2}{c|}{} & \multicolumn{2}{c|}{ Sexo } \\
\cline { 3 - 4 } \multicolumn{2}{c|}{} & Hombre & Mujer \\
\hline \multirow{2}{*}{$\begin{array}{c}\text { Titulación de } \\
\text { mayor rango } \\
\text { académico }\end{array}$} & Diplomado & $2,4 \%$ & $1,8 \%$ \\
\cline { 2 - 4 } & Licenciado & $13,6 \%$ & $15 \%$ \\
\cline { 2 - 4 } & Doctor & $38,7 \%$ & $28,5 \%$ \\
\hline \multicolumn{2}{|c|}{$\mathbf{8 8 4}$} \\
\hline \multicolumn{2}{|c|}{$\mathbf{p = 0 , 0 2}$} \\
\hline
\end{tabular}

- Tiempo invertido en la finalización de la Tesis Doctoral y razones que pudieron demorar este trabajo.

En cuanto al tiempo invertido en la realización de la Tesis Doctoral, ha oscilado fundamentalmente entre los dos y cinco años en un gran número de docentes $(68,9 \%)$, no existiendo diferencias estadísticamente significativas en función del sexo.
La simultaneidad de este trabajo con las actividades docentes $(40,2 \%)$ y con otras tareas investigadoras (14,9\%), la falta de dirección (19,8\%), y el desempeñar otros trabajos fuera del ámbito universitario $(12,5 \%)$, son las razones que parecen tener un mayor peso a la hora de explicar el retraso en la finalización de su Tesis Doctoral.

\begin{tabular}{|c|c|c|c|c|c|c|c|}
\hline & & \multicolumn{2}{|c|}{ Tt al } & \multicolumn{2}{|c|}{ o bbas } & \multicolumn{2}{|c|}{ Mjires } \\
\hline & & $\mathbf{N}$ & $\%$ & $\mathbf{N}$ & $\%$ & $\mathbf{N}$ & $\%$ \\
\hline \multirow{4}{*}{$\begin{array}{c}\text { Año de realización } \\
\text { de la tesis }\end{array}$} & De 2 a 5 & 424 & 68,9 & 239 & 68,9 & 182 & 45,3 \\
\hline & De 5 a10 & 175 & 28,5 & 95 & 27,4 & 78 & 19,4 \\
\hline & Más de 10 & 16 & 2,6 & 13 & 3,7 & 2 & 0,5 \\
\hline & Ncontesta & 283 & 31,4 & 139 & 28,4 & 140 & 34,8 \\
\hline
\end{tabular}




\section{Gráfico 4}

Razones que han retrasado la finalización de la tesis Doctoral

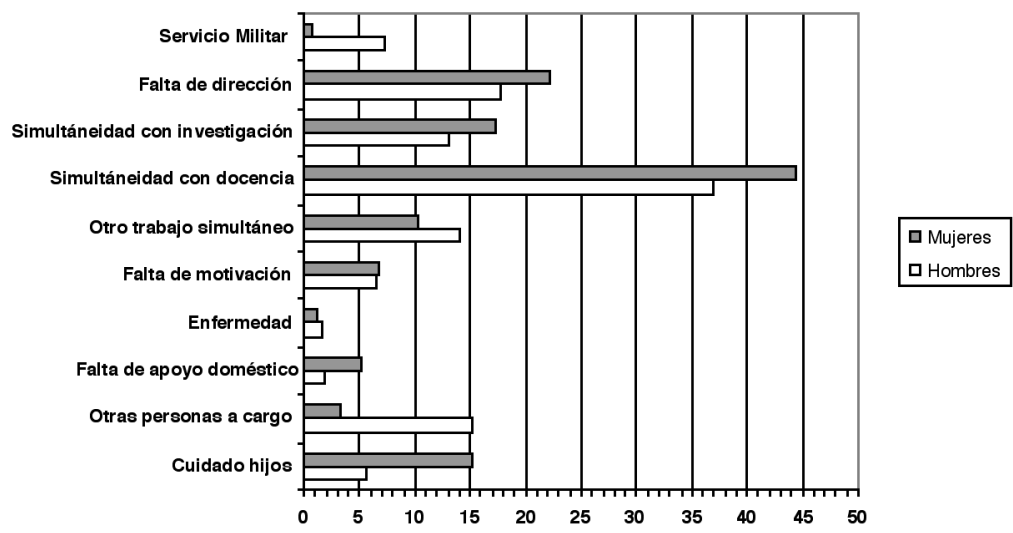

En menor medida, el profesorado alude a otros motivos como el servicio militar, en el caso de los varones $(7,2 \%)$, la falta de motivación, planteada por un porcentaje similar de profesores y profesoras (6,5\% y $6,7 \%$, respectivamente), el cuidado de los hijos $(5,7 \%$ de los profesores $\mathrm{y}$
$15,2 \%$ de profesoras) y la falta de apoyo doméstico $(1,8 \%$ de los profesores y un $5,2 \%$ de las profesoras), razones éstas últimas mayormente señaladas por las docentes que por sus compañeros $(p=0,000$ y $\mathrm{p}=0,006$ ), tal como se observa en las siguientes tablas:

Tabla 14

Influencia del cuidado de los hijos en la finalización de la Tesis Doctoral

\begin{tabular}{|c|l|r|c|}
\cline { 3 - 4 } \multicolumn{2}{c|}{} & \multicolumn{2}{c|}{ Sexo } \\
\cline { 3 - 4 } \multicolumn{2}{c|}{} & Hombre & Mujer \\
\hline \multirow{2}{*}{ Cuidado de hijos } & Si & $3,8 \%$ & $8,2 \%$ \\
\cline { 2 - 4 } & No & $50,9 \%$ & $37,1 \%$ \\
\hline \multicolumn{2}{|c|}{ N Total } & \multicolumn{2}{|c|}{$\mathbf{7 4 6}$} \\
\hline \multicolumn{2}{|c|}{ Phi-cuadrado $=\mathbf{0 2 , 0 0 0}$} \\
\hline
\end{tabular}


Tabla 15

Influencia de la falta de apoyo doméstico en la finalización de la Tesis Doctoral

\begin{tabular}{|c|c|c|c|}
\hline & & \multicolumn{2}{|c|}{ Sew } \\
\hline & & Unbe & Mujer \\
\hline \multirow{2}{*}{$\begin{array}{l}\text { Falta de apoyo } \\
\text { doméstico }\end{array}$} & $\mathbf{S i}$ & $1,2 \%$ & $2,8 \%$ \\
\hline & No & $53,5 \%$ & $42,5 \%$ \\
\hline \multicolumn{2}{|c|}{ Natal } & \multicolumn{2}{|c|}{ c } \\
\hline \multicolumn{2}{|c|}{ Gcuadrado $=\mathbf{6 9 0}$} & \multicolumn{2}{|c|}{$\mathbf{p}=\mathbf{0}$} \\
\hline
\end{tabular}

Sólo hemos encontrado diferencias estadísticamente significativas entre profesores y profesoras en estas dos últimas razones apuntadas (cuidado de hijos y falta de apoyo doméstico), por lo que podemos afirmar que la opinión que da el profesorado, con respecto a los demás motivos que pudieron demorar la realización de su Tesis Doctoral, ha sido similar. Además de las razones comentadas, los docentes, en general, se refieren a otras que también retrasaron la finalización de este trabajo de investigación, entre las que se encuentran: el cambio de área, especialidad o tema de investigación, la falta de apoyo o financiación económica de algún tipo, la dificultad de acceso a determinada documentación necesaria para el desarrollo del trabajo, la demora en la obtención de datos, la simultaneidad de este trabajo con la realización de otros estudios, o con el desempeño de cargos de gestión académica, y las trabas puestas por el director/a de la Tesis Doctoral a distintos aspectos de la misma. En esta misma línea, algunos docentes aducen también la distancia geográfica entre director y doctorando, y la falta de apoyo del Departamento.

\subsection{Perfil Profesional}

- Universidad, tipo de centro en el que se trabaja y años de docencia universitaria

La mayor parte del profesorado pertenece a la Universidad de Valladolid $(45,17 \%)$ y Salamanca $(31,1 \%)$, y trabaja en Facultades y Escuelas Técnicas Superiores $(82,3 \%)$. En cuanto al número de años dedicados a la docencia universitaria, el porcentaje más significativo lo podemos situar en el intervalo comprendido entre los once y veinte años (36,5\%), si bien hay también una proporción importante de profesorado que lleva desempeñando su actividad docente entre cinco y diez años (25,6\%). Son los profesores varones los que manifiestan haber ejercido durante mayor tiempo la actividad docente universitaria $(p=0,038)$, tal como puede apreciarse en la tabla 17.

- Trabajo en otras universidades y/o desempeño de otras actividades profesionales

Es un profesorado que no ha trabajado mayoritariamente en otras universidades, como se puede observar en los datos que 
recogemos en la tabla 18, ni que suele compaginar habitualmente su actividad docente con otra actividad fuera del ámbito universitario.

No hemos observado diferencias estadísticamente significativas entre profesores y profesoras a la hora de haber trabajado como contratados o funcionarios en otra u otras universidades. Sí se aprecian, sin embargo, cuando se les pregunta si realizan otra actividad profesional además de la docencia universitaria, de modo que los profesores manifiestan más frecuentemente que sus compañeras el desempeñar dicha actividad $(\mathrm{p}=0,027)$.

Tabla 16

Universidad, tipo de centro de trabajo y años de docencia universitaria

\begin{tabular}{|c|c|c|c|c|c|c|c|}
\hline & & & & & & & \\
\hline & & \multicolumn{2}{|c|}{ Tt al } & \multicolumn{2}{|c|}{ o Gmbres } & \multicolumn{2}{|c|}{ Mjeres } \\
\hline & & $\mathbf{N}$ & $\%$ & $\mathbf{N}$ & $\%$ & $\mathbf{N}$ & $\%$ \\
\hline \multirow{5}{*}{$\begin{array}{l}\text { hiversidad } \\
\text { de trabajo }\end{array}$} & Burgos & 96 & 10,7 & 54 & 11 & 40 & 10 \\
\hline & León & 112 & 12,4 & 60 & 12,3 & 49 & 12,2 \\
\hline & Salamanca & 280 & 31,1 & 153 & 31,3 & 126 & 31,3 \\
\hline & y ladolid & 407 & 45,17 & 221 & 45,2 & 186 & 46,2 \\
\hline & No contesta & 3 & 0,3 & 1 & 45 & 1 & 0,2 \\
\hline \multirow{3}{*}{$\begin{array}{l}\text { Tp o de } \\
\text { centro }\end{array}$} & Gcultad / & 729 & 82,3 & 394 & 81,6 & 327 & 83 \\
\hline & Fc.bivers. & 157 & 17,7 & 89 & 18,4 & 67 & 17 \\
\hline & No contesta & 7 & 0,8 & 6 & 1,2 & 5 & 1,2 \\
\hline \multirow{4}{*}{$\begin{array}{c}\text { A! os de docencia } \\
\text { universitaria }\end{array}$} & Mores de 5 a $\quad$ os & 160 & 17,8 & 82 & 16,8 & 77 & 19,2 \\
\hline & D5a ! os & 231 & 25,6 & 125 & 25,6 & 106 & 26,4 \\
\hline & Dea latos & 329 & 36,5 & 166 & 33,9 & 157 & 39,1 \\
\hline & M"s de en ! os & 181 & 20,1 & 116 & 23,7 & 62 & 15,4 \\
\hline
\end{tabular}

Tabla 17

Años de docencia universitaria

\begin{tabular}{|c|c|c|c|c|}
\cline { 2 - 5 } \multicolumn{1}{c|}{} & \multicolumn{2}{|c|}{ Medias } & \multicolumn{2}{c|}{ Prueba T } \\
\cline { 2 - 5 } & $\mathbf{H}$ & $\mathbf{M}$ & $\mathbf{t}$ \\
\hline Años de docencia universitaria & 2,65 & 2,21 & 2,074 & 0,038 \\
\hline
\end{tabular}


Tabla 18

Trabajo en otras universidades y actividades profesionales fuera del ámbito universitario

\begin{tabular}{|c|c|c|c|c|c|c|c|}
\hline & & \multirow{2}{*}{\multicolumn{2}{|c|}{ Total }} & & & & \\
\hline & & & & \multicolumn{2}{|c|}{ Hombres } & \multicolumn{2}{|c|}{ Mujeres } \\
\hline & & $\mathbf{N}$ & $\%$ & $\mathbf{N}$ & $\%$ & $\mathbf{N}$ & $\%$ \\
\hline \multirow{3}{*}{$\begin{array}{l}\text { Trabajo en otras } \\
\text { Universidades }\end{array}$} & $\mathbf{S i}$ & 210 & 23,5 & 120 & 24,8 & 88 & 21,9 \\
\hline & No & 683 & 76,5 & 364 & 75,2 & 312 & 77,6 \\
\hline & No contesta & 7 & 0,8 & 4 & 0,8 & 2 & 0,5 \\
\hline \multirow{3}{*}{$\begin{array}{c}\text { Otra actividad } \\
\text { profesional }\end{array}$} & $\mathbf{S i}$ & 139 & 15,7 & 88 & 18,1 & 50 & 12,7 \\
\hline & No & 749 & 84,3 & 397 & 81,9 & 344 & 87,3 \\
\hline & No contesta & 11 & 1,2 & 3 & 0,6 & 7 & 1,7 \\
\hline
\end{tabular}

Tabla 19

Sexo y desempeño de otra actividad profesional

\begin{tabular}{|c|c|c|c|}
\hline & & \multicolumn{2}{|c|}{ Sed } \\
\hline & & Stmbe & Mujer \\
\hline \multirow{2}{*}{$\begin{array}{l}\text { Desempeño de otra } \\
\text { actividad profesional }\end{array}$} & $\mathbf{S i}$ & $18,1 \%$ & $12,7 \%$ \\
\hline & No & $81,9 \%$ & $87,3 \%$ \\
\hline \multicolumn{2}{|c|}{ N atal } & \multicolumn{2}{|c|}{ 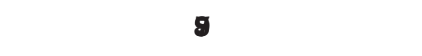 } \\
\hline \multicolumn{2}{|c|}{ Gcuadrado $=\mathbb{4 8}$} & \multicolumn{2}{|c|}{$p=0027$} \\
\hline
\end{tabular}

- Categoría profesional actual de los docentes

Las categorías profesionales de la mayor parte del profesorado participante son, por este orden, las de Titular de Universidad (32,6\%), Titular de Escuela Universitaria (21,3\%), Ayudante (11,4\%), Asociado a ocho horas (9\%) y Asociado a seis horas $(10,1 \%)$. Aunque en todas las categorías, a excepción de las de Ayudante y Asociado a 8 horas, se da una mayor proporción de varones, las diferencias principales entre sexos las podemos situar en la categoría de Catedrático, así como también, aunque ya en menor medida, en las de Titular de Universidad y Catedrático de Escuela Universitaria $(p=0,000)$. En todos estos casos se aprecia la presencia mayoritaria de profesorado varón.

Estos datos confirman los recogidos en otros estudios anteriores (Almarcha y González, 1994; Barbera, Lafuente y Sarrió, 1998), en los que se evidencia que aunque los porcentajes femeninos en la mayor parte de las categorías docentes, son siempre más 
bajos, dichos porcentajes descienden de modo especialmente significativo en la categoría de Catedrático de Universidad. En este sentido, coincidimos con Almarcha y Gónzalez (1994: 129), al afirmar que:
"La barrera de cristal para la mayoría del profesorado es la titularidad. No obstante, esta situación es diferente si comparamos profesores y profesoras. El impacto de parada es muy superior, como media, entre las mujeres. La situación se estanca cuando nos centramos en la categoría de catedráticos".

Tabla 20

Sexo y categorías profesionales actuales de los docentes

\begin{tabular}{|c|c|c|c|}
\hline & & \multicolumn{2}{|c|}{ Sexo } \\
\hline & & Hombre & Mujer \\
\hline \multirow{8}{*}{$\begin{array}{c}\text { Categorías } \\
\text { profesionales } \\
\text { actuales }\end{array}$} & Ayudante & $5,4 \%$ & $6,4 \%$ \\
\hline & Asociado 8 horas & $4,1 \%$ & $5,1 \%$ \\
\hline & Asociado 6 horas & $6,4 \%$ & $4 \%$ \\
\hline & Asociado 3 horas & $2,2 \%$ & $1 \%$ \\
\hline & Titular E.U. & $11,4 \%$ & $10,2 \%$ \\
\hline & Catedrático E.U. & $3,1 \%$ & $1,5 \%$ \\
\hline & Titular Universidad & $18,1 \%$ & $15,2 \%$ \\
\hline & Catedrático Universidad & $4,8 \%$ & $1 \%$ \\
\hline \multicolumn{2}{|r|}{ N Total } & \multicolumn{2}{|c|}{874} \\
\hline \multicolumn{2}{|c|}{ Chi-cuadrado $=\mathbf{2 9 , 0 5 1}$} & \multicolumn{2}{|c|}{$\mathbf{p}=\mathbf{0 , 0 0 0}$} \\
\hline
\end{tabular}

- Categorías profesionales por las que han pasado los docentes

En cuanto a las categorías profesionales por las que ha ido pasando el profesorado, destacan fundamentalmente las de Ayudante $(64,6 \%)$ y Titular de Universidad (34,3\%), seguidas de las de Asociado a seis horas $(24,6 \%)$ y Titular de Universidad interino $(24,2 \%)$.

El género parece ser de nuevo una variable que nos permite determinar algunas diferencias en las categorías profesionales por las que han ido pasando los docentes. Concretamente, tales diferencias se sitúan en las categorías de Ayudante, Catedrático de Escuela Universitaria y Catedrático de Universidad, siendo los profesores varones los que han pasado mayoritariamente por las mismas, o se encuentran en el momento actual en la categoría de Catedrático de Universidad ( $\mathrm{p}=0,000)$. Por tanto, observamos que el acceso a la categoría de Catedrático sigue siendo algo más propio del colectivo masculino. 
Tabla 21

Categorías profesionales por las que han pasado los docentes

\begin{tabular}{|c|c|c|c|c|c|c|c|}
\hline & & \\
\hline & & \multicolumn{2}{|c|}{ Total } & \multicolumn{2}{|c|}{ Hombres } & \multicolumn{2}{|c|}{ Mujeres } \\
\hline & & $\mathbf{N}$ & $\%$ & $\mathbf{N}$ & $\%$ & $\mathbf{N}$ & $\%$ \\
\hline \multirow{10}{*}{$\begin{array}{l}\text { Categorú as } \\
\text { profesionales por } \\
\text { las que ha pasado }\end{array}$} & Ayudante & 582 & 64,6 & 302 & 61,8 & 275 & 68,4 \\
\hline & Asociado 8 horas & 199 & 22,1 & 98 & 20,1 & 100 & 24,9 \\
\hline & Asociado 6 horas & 222 & 24,6 & 127 & 26 & 95 & 23,6 \\
\hline & Asociado 3 horas & 72 & 8 & 39 & 8 & 31 & 7,7 \\
\hline & Titular de E.U. interino & 164 & 18,2 & 85 & 17,4 & 76 & 18,9 \\
\hline & Titular de Univ. interino & 218 & 24,2 & 121 & 24,7 & 94 & 23,4 \\
\hline & Titular de E.U. & 203 & 22,5 & 111 & 22,7 & 90 & 22,4 \\
\hline & Catedrótico E.U. & 44 & 4,9 & 30 & 6,1 & 13 & 3,2 \\
\hline & Titular de Universidad & 309 & 34,3 & 177 & 36,2 & 129 & 32,1 \\
\hline & Catedrótico Universidad & 52 & 5,8 & 41 & 8,4 & 10 & 2,5 \\
\hline
\end{tabular}

- Tiempo de docencia ejercida como profesor no numerario

El tiempo de docencia como profesor no numerario ha oscilado en un 47,9\% de los casos, entre los cinco y diez años, si bien hay un porcentaje importante de profesorado que ha estado en esta categoría menos de cinco años $(29,4 \%)$. No se dan diferencias estadísticamente significativas entre profesores $\mathrm{y}$ profesoras en este tiempo de docencia, aspecto que evidenciamos también en la investigación de Almarcha y González (1994). En consecuencia, podemos afirmar que el sexo no es una variable que condicione el acceso a plazas docentes ordinarias. Como señalan las citadas autoras, "las mujeres no emplean más años que sus colegas en convertirse en los cuerpos de élite" (Almarcha y González, 1994:132).

Tabla 22

Tiempo de docencia como profesor no numerario

\begin{tabular}{|c|c|c|c|c|c|c|c|}
\hline & & \multicolumn{2}{|c|}{ Tt al o } & \multicolumn{2}{|c|}{ Llmbes } & \multicolumn{2}{|c|}{ Mujeres } \\
\hline & & $\mathbf{N}$ & $\%$ & $\mathbf{N}$ & $\%$ & $\mathbf{N}$ & $\%$ \\
\hline \multirow{5}{*}{$\begin{array}{c}\text { me mpo } \\
\text { de docencia } \\
\text { / profesor no } \\
\text { numerario }\end{array}$} & Menos de 5 años & 266 & 29,4 & 150 & 30,7 & 102 & 28,1 \\
\hline & De 5 a 10 años & 433 & 47,9 & 233 & 47,7 & 196 & 48,7 \\
\hline & De 11 a 20 años & 124 & 13,6 & 62 & 12,5 & 60 & 14,6 \\
\hline & M! s de 20 años & 16 & 1,6 & 10 & 2 & 5 & 1,1 \\
\hline & No contesta & 62 & 6,9 & 34 & 7 & 27 & 6,7 \\
\hline
\end{tabular}




\section{- Tramos de docencia e investigación}

La ley permite que los profesores soliciten la concesión de un tramo de docencia y de investigación cada seis años, debiendo acreditar para ello una buena evaluación docente y un número de publicaciones suficiente ante el Ministerio de Educación. Un porcentaje significativo de los docentes no tiene tramos de docencia $(37,9 \%)$ ni de investigación (60,8\%), lo que se debe interpretar teniendo en cuenta que un $18 \%$ de los docentes lleva menos de cinco años en la docencia universitaria, y ello les imposibilita la obtención de este tipo de incentivo.

Entre los que manifiestan tener reconocido algún tramo, destacan los que poseen entre uno y dos (22,7\% para tramos de docencia y $20,2 \%$ para tramos de investigación). No ha sido frecuente la denegación de tramos de docencia $(1,4 \%)$ aunque sí la correspondiente a tramos de investigación $(12,2 \%)$.

Los profesores varones afirman tener más tramos de docencia reconocidos, en consonancia con el hecho de que son también éstos los que llevan un mayor número de años ejerciendo la docencia universitaria, tal y como se puso de manifiesto en un punto anterior $(p=0,021)$. Sin embargo, no se han observado diferencias estadísticamente significativas entre sexos en cuanto a tramos de investigación.

Tabla 23

Tramos de docencia y de investigación

\begin{tabular}{|c|c|c|c|c|c|c|c|}
\hline & & \multicolumn{2}{|c|}{ Total } & \multicolumn{2}{|c|}{ Hombres } & \multicolumn{2}{|c|}{ Mujeres } \\
\hline & & $\mathbf{N}$ & $\%$ & $\mathbf{N}$ & $\%$ & $\mathbf{N}$ & $\%$ \\
\hline \multirow{5}{*}{$\begin{array}{c}\text { Tramos } \\
\text { de docencia } \\
\text { reconocidos }\end{array}$} & $\mathbf{0}$ & 342 & 37,9 & 179 & 36,6 & 160 & 39,8 \\
\hline & $1-2$ & 204 & 22,7 & 106 & 13,6 & 96 & 23,9 \\
\hline & $3-4$ & 176 & 19,6 & 101 & 20,7 & 73 & 18,2 \\
\hline & $5-6$ & 92 & 10,2 & 56 & 11,5 & 43 & 8,2 \\
\hline & No contesta & 85 & 9,4 & 45 & 9,2 & 40 & 10 \\
\hline \multirow{3}{*}{$\begin{array}{c}\text { Tramos } \\
\text { de docencia } \\
\text { denegados }\end{array}$} & $\mathbf{S i}$ & 13 & 1,4 & 7 & 1,4 & 5 & 1,2 \\
\hline & No & 477 & 52,9 & 269 & 55 & 202 & 50,2 \\
\hline & No contesta & 409 & 45,4 & 211 & 43,1 & 195 & 48,5 \\
\hline \multirow{5}{*}{$\begin{array}{l}\text { Tramos de } \\
\text { investigación } \\
\text { reconocidos }\end{array}$} & 0 & 547 & 60,8 & 283 & 57,9 & 258 & 64,1 \\
\hline & $1-2$ & 182 & 20,2 & 104 & 21,3 & 78 & 19,4 \\
\hline & $3-4$ & 65 & 7,2 & 41 & 8,4 & 23 & 5,7 \\
\hline & $5-6$ & 8 & 0,9 & 6 & 1,2 & 1 & 0,2 \\
\hline & No contesta & 99 & 11 & 55 & 11,2 & 42 & 10,4 \\
\hline \multirow{3}{*}{$\begin{array}{c}\text { Tramos de } \\
\text { investigación } \\
\text { denegados }\end{array}$} & $\mathbf{S i}$ & 110 & 12,2 & 66 & 13,5 & 41 & 10,2 \\
\hline & No & 267 & 29,6 & 151 & 30,9 & 113 & 28,1 \\
\hline & No contesta & 521 & 57,8 & 270 & 55,2 & 247 & 61,2 \\
\hline
\end{tabular}


Tabla 24

Sexo y tramos de docencia reconocidos

\begin{tabular}{|c|c|c|c|c|}
\cline { 2 - 5 } & \multicolumn{2}{|c|}{ Medias } & \multicolumn{2}{c|}{ Prueba T } \\
\cline { 2 - 5 } & $\mathbf{H}$ & $\mathbf{M}$ & $\mathbf{t}$ & $\mathbf{p}$ \\
\hline Tramos de docencia reconocidos & 1,44 & 1,32 & 5,324 & 0,021 \\
\hline
\end{tabular}

- Aspiración de concluir la carrera docente como Catedrático

Aunque son muchos los docentes que manifiestan no tener la aspiración de concluir la carrera docente como Catedrático (44\%), son los profesores varones los que en mayor medida se plantean el acceso a esta categoría profesional como culminación de su trayectoria docente $(\mathrm{p}=0,000)$.

Entre las razones que apunta el profesorado que no se plantea culminar su carrera como catedráticos, encontramos fundamentalmente la de no tener ambición o interés por alcanzar ese objetivo (24,9\%), seguida de la falta de oportunidades que brinda la Universidad (10,8\%), siendo esta última razón especialmente señalada por las profesoras. A excepción de ésta, no hemos encontrado diferencias entre ambos colectivos, en los restantes motivos argumentados.
Los docentes aluden también a otras razones para no optar a una cátedra, entre las que encontramos, por una parte, algunas de tipo personal, como son la priorización de otros aspectos de la vida, considerados más importantes e incompatibles con la carrera docente, o la incorporación a la carrera docente universitaria relativamente tardía; y otras de carácter profesional y/o institucional, entre las que citan: La existencia de numerosos candidatos delante, la desilusión que provoca el funcionamiento del propio sistema, al valorar injustamente los tramos de investigación, la endogamia departamental y universitaria, la falta de una mayor horizontalidad en la estructura académica, el hecho de tener que pasar nuevamente por otra oposición, o la existencia de otras vías para finalizar la carrera docente.

Sexo y aspiraciones de culminar la carrera docente como Catedrático

\begin{tabular}{|c|c|c|c|}
\hline & & \multicolumn{2}{|c|}{ Sexo } \\
\hline & & Hombre & Mujer \\
\hline \multirow{2}{*}{$\begin{array}{l}\text { Culminación } \\
\text { como catedrático }\end{array}$} & $\mathbf{S i}$ & $28,6 \%$ & $16,7 \%$ \\
\hline & No & $24,6 \%$ & $30,1 \%$ \\
\hline \multicolumn{2}{|c|}{ N Total } & \multicolumn{2}{|c|}{714} \\
\hline \multicolumn{2}{|c|}{ Chi-cuadrado $=23,392$} & \multicolumn{2}{|c|}{$p=0,000$} \\
\hline
\end{tabular}


Tabla 26

Razones por las que no se plantean culminar su carrera docente como Catedráticos

\begin{tabular}{|c|c|c|c|c|c|c|}
\hline & \multicolumn{2}{|c|}{ Tt al } & \multicolumn{2}{|c|}{ Gimbices } & \multicolumn{2}{|c|}{ Meres } \\
\hline & $\mathbf{N}$ & $\%$ & $\mathbf{N}$ & $\%$ & $\mathbf{N}$ & $\%$ \\
\hline No tiene suficiente curriculum & 96 & 10,7 & 37 & 7,6 & 59 & 14,7 \\
\hline No tiene ambición o interés por ese objetivo & 224 & 24,9 & 100 & 20,4 & 121 & 30,1 \\
\hline No tiene apoyo del departamento & 50 & 5,5 & 20 & 4,1 & 28 & 7 \\
\hline ile ne demasiadas obligaciones & 67 & 7,4 & 28 & 5,7 & 38 & 9,5 \\
\hline La biversidad no ofrece esta oportunidad & 97 & 10,8 & 32 & 6,5 & 63 & 15,7 \\
\hline
\end{tabular}

\subsection{Actividad docente}

- Asignaturas impartidas en el curso 2000-2001, número de créditos y tipo

La media de créditos que imparten los profesores y profesoras de la muestra en un curso académico es muy similar $(16,70 \%$ y $16,68 \%)$. En cuanto al tipo de asignatura, los datos recogidos evidencian que las profesoras suelen impartir más asignaturas troncales y obligatorias, mientras que los profesores se encargan en mayor medida de materias de carácter optativo.

Número de créditos y tipo de asignaturas impartidas en el curso 2000-01

\begin{tabular}{|c|c|c|}
\hline & \multicolumn{2}{|c|}{$N^{\circ}$ de créditos } \\
\hline & Simbes & Mujeres \\
\hline & 8171 & 6705,8 \\
\hline & \multicolumn{2}{|c|}{ Media de créditos } \\
\hline & 16,70 & 16,68 \\
\hline & \multicolumn{2}{|c|}{ Tipo de asignaturas impartida } \\
\hline Troncal & 279 & 489 \\
\hline Egatoria & 203 & 293 \\
\hline Ptatix & 295 & 264 \\
\hline
\end{tabular}


- Asignaturas diferentes impartidas a lo largo de la carrera docente

Una gran parte del profesorado ha impartido entre una y cinco asignaturas diferentes a lo largo de su trayectoria docente $(57,2 \%)$, siendo también numerosos los que han explicado entre seis y diez materias de diversa índole $(32,7 \%)$. Pero sin duda, lo más llamativo se centra en la detección de profesores que en el transcurso de los años han enseñado más de 15 asignaturas diferentes. Este hecho supone, no sólo el sobreesfuerzo para estos docentes, sino inevitablemente una repercusión importante en la calidad de la docencia. No se han constatado diferencias estadísticamente significativas en la distribución de la carga docente entre el profesorado de uno y otro sexo.

Tabla 28

Asignaturas diferentes impartidas a lo largo de carrera docente

\begin{tabular}{|c|c|c|c|c|c|c|c|}
\hline & & \multicolumn{2}{|c|}{ Total } & \multicolumn{2}{|c|}{ Hombres } & \multicolumn{2}{|c|}{ Mujeres } \\
\hline & & $\mathbf{N}$ & $\%$ & $\mathbf{N}$ & $\%$ & $\mathbf{N}$ & $\%$ \\
\hline \multirow{6}{*}{$\begin{array}{l}\text { Númeroóde } \\
\text { asignaturas } \\
\text { diferentes } \\
\text { impartidas }\end{array}$} & $\mathbf{0}$ & 5 & 0,6 & 1 & 0,2 & 3 & 0,7 \\
\hline & $1-5$ & 516 & 57,2 & 283 & 57,8 & 227 & 56,5 \\
\hline & $6-10$ & 295 & 32,7 & 157 & 32 & 137 & 34,1 \\
\hline & 11-15 & 49 & 5,5 & 28 & 5,7 & 21 & 5,1 \\
\hline & M sódeó15 & 12 & 1,2 & 4 & 0,8 & 6 & 1,3 \\
\hline & Noócontesta & 24 & 2,7 & 16 & 3,3 & 8 & 2 \\
\hline
\end{tabular}

- Participación en programas

de Doctorado

Son muchos los docentes que participan en uno o dos programas de Doctorado $(48,2 \%)$, en los que imparten entre uno y cinco créditos $(31,9 \%)$, tutorizando durante el periodo de investigación, entre uno y cinco alumnos (31,8\%). Las pruebas estadísticas efectuadas no han mostrado diferencias significativas en función del sexo en ninguna de las variables relacionadas con la participación en estos programas.
- Participación en Cursos de Postgrado

La colaboración del profesorado en Programas de Postgrado no es especialmente relevante (un $61,6 \%$ manifiesta no participar en los mismos), si bien son los profesores quienes participan en mayor grado que las profesoras, desarrollando esta labor en uno o en dos programas (27,6\%). 
Tabla 29

Participación en Programas de Doctorado

\begin{tabular}{|c|c|c|c|c|c|c|c|}
\hline & & \\
\hline & & \multicolumn{2}{|c|}{ Total } & \multicolumn{2}{|c|}{ Hombres } & \multicolumn{2}{|c|}{ Mujeres } \\
\hline & & $\mathbf{N}$ & $\%$ & $\mathbf{N}$ & $\%$ & $\mathbf{N}$ & $\%$ \\
\hline \multirow{3}{*}{$\begin{array}{l}\text { Participación } \\
\text { en programas } \\
\text { de doctorado }\end{array}$} & $\mathbf{S i}$ & 500 & 55,5 & 283 & 57,9 & 212 & 52,7 \\
\hline & No & 386 & 42,8 & 200 & 40,9 & 181 & 45 \\
\hline & No contesta & 15 & 1,7 & 6 & 1,2 & 9 & 2,2 \\
\hline \multirow{4}{*}{$\begin{array}{c}\text { N\# mero de } \\
\text { programas de } \\
\text { doctorado en } \\
\text { los que participa }\end{array}$} & $\mathbf{0}$ & 421 & 46,7 & 218 & 44,6 & 198 & 49,3 \\
\hline & 1-2 & 434 & 48,2 & 247 & 50,6 & 182 & 45,2 \\
\hline & $3-4$ & 42 & 4,7 & 23 & 4,7 & 19 & 4,7 \\
\hline & M\$s de 5 & 4 & 0,4 & 1 & 0,2 & 3 & 0,6 \\
\hline \multirow{5}{*}{$\begin{array}{l}\text { Crúditos teóricos } \\
\text { de doctorado } \\
\text { impartidos } \\
\text { (curso 2000-2001) }\end{array}$} & $0-1$ & 6 & 0,6 & 2 & 0,4 & 4 & 0,9 \\
\hline & $1-5$ & 287 & 31,9 & 159 & 32,4 & 129 & 31,3 \\
\hline & 6-10 & 65 & 7,2 & 38 & 7,7 & 28 & 7 \\
\hline & 11-15 & 24 & 2,6 & 11 & 2,2 & 10 & 2,4 \\
\hline & M\$s de 15 & 24 & 2,6 & 18 & 3,6 & 6 & 1,3 \\
\hline \multirow{5}{*}{$\begin{array}{l}\text { Alumnos de } \\
\text { doctorado } \\
\text { tutorizados } \\
\text { en ese curso }\end{array}$} & o & 563 & 62,5 & 295 & 60,3 & 261 & 64,9 \\
\hline & $1-5$ & 287 & 31,8 & 164 & 33,5 & 120 & 29,7 \\
\hline & 6-10 & 42 & 4,7 & 26 & 5,2 & 16 & 3,9 \\
\hline & 11-15 & 8 & 0,8 & 4 & 0,8 & 4 & 0,9 \\
\hline & M\$s de 15 & 1 & 0,1 & 0 & 0 & 1 & 0,2 \\
\hline
\end{tabular}


Tabla 30

Participación en Cursos de Postgrado

\begin{tabular}{|c|c|c|c|c|c|c|c|}
\hline & & \multicolumn{2}{|c|}{ Total } & \multicolumn{2}{|c|}{ Hombres } & \multicolumn{2}{|c|}{ Mujeres } \\
\hline & & $\mathbf{N}$ & $\%$ & $\mathbf{N}$ & $\%$ & $\mathbf{N}$ & $\%$ \\
\hline \multirow{3}{*}{$\begin{array}{l}\text { Participación } \\
\text { en cursos de } \\
\text { posgrado }\end{array}$} & $\mathbf{S i}$ & 267 & 29,6 & 156 & 31,9 & 105 & 26,1 \\
\hline & No & 555 & 61,6 & 289 & 59,1 & 263 & 65,4 \\
\hline & No contesta & 79 & 8,8 & 44 & 9 & 34 & 8,5 \\
\hline \multirow{4}{*}{$\begin{array}{l}\text { Número de } \\
\text { cursos en los } \\
\text { que participa }\end{array}$} & o & 634 & 70,4 & 332 & 67,9 & 298 & 74,1 \\
\hline & $1-2$ & 248 & 27,6 & 145 & 29,7 & 98 & 24,4 \\
\hline & $3-4$ & 16 & 1,7 & 10 & 2 & 5 & 1,2 \\
\hline & $5-6$ & 3 & 0,3 & 2 & 0,4 & 1 & 0,2 \\
\hline
\end{tabular}

\subsection{Cargos de dirección y de gestión}

- $\quad$ Interés y sentimientos de capacidad por desempeñar cargos de dirección y gestión

Los docentes se sienten por lo general capaces de ocupar cargos de dirección y gestión en la institución universitaria $(87,8 \%)$, aunque manifiestan no tener interés por desempeñarlos $(59,5 \%)$. Esta falta de interés puede ser debida, como apunta Fernández (1989), a que se trata de cargos que exigen mucha dedicación, además de tener una duración media de cuatro años, lo que puede suponer un fuerte desgaste personal. No obstante, es el colectivo docente masculino el que manifiesta sentirse más capaz $(p=0,009)$ y el que, a su vez, muestra mayor interés por desempeñar estos cargos $(\mathrm{p}=0,033)$.

Tabla 31

Capacidad para desempeñar cargos de dirección y gestión

\begin{tabular}{|c|c|c|c|}
\hline & & \multicolumn{2}{|c|}{ Sexo } \\
\hline & & Hombre & Mujer \\
\hline \multirow{2}{*}{$\begin{array}{l}\text { Se siente } \\
\text { capaz }\end{array}$} & $\mathbf{S i}$ & $51,6 \%$ & $39,9 \%$ \\
\hline & No & $3,5 \%$ & $5,0 \%$ \\
\hline \multicolumn{2}{|c|}{ N Total } & \multicolumn{2}{|c|}{855} \\
\hline \multicolumn{2}{|c|}{ Chi-cuadrado $=6,316$} & \multicolumn{2}{|c|}{$p=0,009$} \\
\hline
\end{tabular}


Tabla 32

Interés por desempeñar cargos de dirección y gestión

\begin{tabular}{|c|l|c|c|}
\cline { 3 - 4 } \multicolumn{2}{c|}{} & \multicolumn{2}{c|}{ Se } \\
\cline { 3 - 4 } \multicolumn{2}{c|}{} & bmbe & Mujer \\
\hline \multirow{2}{*}{ Tiene interés } & Si & $22,1 \%$ & $14,9 \%$ \\
\cline { 2 - 4 } & No & $33,4 \%$ & $29,6 \%$ \\
\hline \multicolumn{2}{|c|}{ N Total } & \multicolumn{2}{|c|}{$\mathbf{8 \pi}$} \\
\hline \multicolumn{2}{|c|}{ Gcuadrado $\mathbf{8 2}$} & $\mathbf{p} \neq$ \\
\hline
\end{tabular}

Los motivos por los que las profesoras se sienten menos capaces e interesadas por asumir la responsabilidad que conlleva este tipo de cargos, pueden ser muy diversos, pero nos interesa resaltar especialmente uno, al que suelen referirse algunos estudios relativos al tema (Fernández, 1989), y que nuestro equipo de investigación también tuvo ocasión de constatar en el grupo de discusión efectuado con algunos docentes. Nos estamos refiriendo al esfuerzo que supone para las profesoras, especialmente las que están casadas y tienen hijos, el tener que compaginar las actividades docentes e investigadoras con tareas propiamente familiares, exigidas en muchas ocasiones como rol social. Ello hace que los cargos de dirección y gestión tiendan a ocupar lugares secundarios entre sus prioridades.
- Participación en Órganos

Unipersonales

Por lo general, es escaso el porcentaje de profesorado que ha desempeñado o está desempeñando cargos en Órganos Unipersonales. Destaca únicamente la participación de una mayor proporción de docentes en los cargos de Secretario/a de Departamento $(26,5 \%)$ y de Vicedecano/a $(21,8 \%)$; hecho razonable si se tiene en cuenta que estos cargos son numéricamente más abundantes en el entorno universitario. Hay que destacar también que aunque los porcentajes de representación de profesores y profesoras en estos cargos son poco relevantes, parece existir una mayor tendencia por parte de los primeros, a la participación en los mismos. 
Tabla 33

Cargo en Órganos Unipersonales y número de años de permanencia en los mismos

\begin{tabular}{|c|c|c|c|c|c|c|c|c|}
\hline \multirow{2}{*}{$\begin{array}{c}\text { Órganos } \\
\text { Unipersonales }\end{array}$} & \multicolumn{2}{|c|}{ En el pasado } & \multicolumn{2}{|c|}{ Atualmente } & \multicolumn{4}{|c|}{$\mathbf{N}^{\circ}$ de a! os / Brcentajes } \\
\hline & bimbres & Mjeres & bimbres & Mjeres & \multicolumn{2}{|c|}{ Embres } & \multicolumn{2}{|c|}{ Myeres } \\
\hline Rector/a & $0,2 \%$ & & & & & & & \\
\hline \multirow{3}{*}{ Vicerrectorado } & \multirow{3}{*}{$0,8 \%$} & \multirow{3}{*}{$0,5 \%$} & \multirow{3}{*}{$0,8 \%$} & \multirow{3}{*}{$0,2 \%$} & $1-4$ & 1,2 & $1-4$ & 0,7 \\
\hline & & & & & $5-8$ & 0,2 & $5-8$ & 0,2 \\
\hline & & & & & Más de 8 & 0,2 & Más de 8 & - \\
\hline \multirow{3}{*}{$\begin{array}{c}\text { Decanato } \\
\text { o dirección } \\
\text { de centros }\end{array}$} & \multirow{3}{*}{$3,9 \%$} & \multirow{3}{*}{$2,7 \%$} & \multirow{3}{*}{$2,2 \%$} & \multirow{3}{*}{$1,5 \%$} & $1-4$ & 3,8 & $1-4$ & 2,2 \\
\hline & & & & & $5-8$ & 1,8 & $5-8$ & 1,2 \\
\hline & & & & & Más de 8 & 0,4 & Más de 8 & - \\
\hline \multirow{3}{*}{$\begin{array}{c}\text { Vicedecanato } \\
\text { o subdirección }\end{array}$} & \multirow{3}{*}{$9,6 \%$} & \multirow{3}{*}{$6 \%$} & \multirow{3}{*}{$3,7 \%$} & \multirow{3}{*}{$2,5 \%$} & $1-3$ & 8,7 & $1-3$ & 3,9 \\
\hline & & & & & $4-6$ & 2,4 & $4-6$ & 3,7 \\
\hline & & & & & Más de 6 & 0,8 & Más de 6 & 0,2 \\
\hline \multirow{3}{*}{$\begin{array}{c}\text { Secretaría } \\
\text { de Facultad } \\
\text { o Escuela }\end{array}$} & \multirow{3}{*}{$5,3 \%$} & \multirow{3}{*}{$2,7 \%$} & \multirow{3}{*}{$2 \%$} & \multirow{3}{*}{$1,2 \%$} & $1-3$ & 5,1 & $1-3$ & 2,1 \\
\hline & & & & & $4-6$ & 1,4 & $4-6$ & 1,4 \\
\hline & & & & & Más de 6 & 0,8 & Más de 6 & 0,5 \\
\hline \multirow{4}{*}{$\begin{array}{c}\text { Dirección de } \\
\text { Departamento }\end{array}$} & \multirow{4}{*}{$8,2 \%$} & \multirow{4}{*}{$4 \%$} & \multirow{4}{*}{$5,5 \%$} & \multirow{4}{*}{$2 \%$} & Menos de 1 & 0,2 & Menos de 1 & - \\
\hline & & & & & $1-3$ & 4,4 & $1-3$ & 3,4 \\
\hline & & & & & $4-6$ & 2,4 & $4-6$ & 0,9 \\
\hline & & & & & Más de 6 & 3,2 & Más de 6 & 0,9 \\
\hline \multirow{4}{*}{$\begin{array}{c}\text { Secretaría de } \\
\text { Departamento }\end{array}$} & \multirow{4}{*}{$9,8 \%$} & & & & Menos de 1 & 0,4 & Menos de 1 & - \\
\hline & & $8 \%$ & $47 \%$ & $4 \%$ & $1-3$ & 5,6 & $1-3$ & 1,8 \\
\hline & & & & & $4-6$ & 4,9 & $4-6$ & 2,7 \\
\hline & & & & & Más de 6 & 2,4 & Más de 6 & 0,4 \\
\hline
\end{tabular}

En cuanto al número de años desempeñando estos cargos, sólo hemos podido constatar diferencias estadísticamente significativas entre profesores y profesoras, en los cargos de Dirección y Secretaría de Departamento, siendo los primeros quienes más tiempo permanecen en ellos $(\mathrm{p}=0,016)$. 
Tabla 34

Diferencias en función del sexo en el número de años como Director de Departamento

$\mathrm{N}^{\circ}$ de años como Director/a de Dpto

\begin{tabular}{|c|c|}
\hline \multicolumn{2}{|c|}{ Medias } \\
\hline $\mathbf{H}$ & $\mathbf{M}$ \\
\hline 5,607 & 3,682 \\
\hline
\end{tabular}

\begin{tabular}{|c|c|}
\hline \multicolumn{2}{|c|}{ Prueba T } \\
\hline $\mathbf{t}$ & $\mathbf{p}$ \\
\hline 2,477 & 0,016 \\
\hline
\end{tabular}

- Participación en Órganos

\section{Colegiados}

Sumando los porcentajes de profesores y profesoras que participan en cada uno de estos órganos, podemos afirmar que dicha participación es ma- yoritariamente masculina en el Claustro Universitario $(38,2 \%)$ y Claustro de Doctores $(17,1 \%)$, mientras que la representación de profesoras es mayor que la de sus compañeros en el Consejo Social $(24,2 \%)$ y en la Comisión de Garantías al Universitario $(13,5 \%)$.

Tabla 35

Participación en Órganos Colegiados

\begin{tabular}{|c|c|c|c|c|c|c|c|c|}
\hline \multirow{2}{*}{$\begin{array}{c}\text { Órganos } \\
\text { Colegiados }\end{array}$} & \multicolumn{2}{|c|}{ En el pasado } & \multicolumn{2}{|c|}{ Atualmente } & \multicolumn{4}{|c|}{$\mathbf{N}^{\circ}$ de a! os } \\
\hline & Gmbres & Mjeres & bimbres & Meres & bIm & & & \\
\hline \multirow{3}{*}{$\begin{array}{c}\text { Consejo } \\
\text { Social }\end{array}$} & \multirow{3}{*}{0,8} & \multirow{3}{*}{14,2} & \multirow{3}{*}{-} & \multirow{3}{*}{10} & $1-4$ & 0,8 & $1-4$ & 8,5 \\
\hline & & & & & $5-8$ & - & $5-8$ & 2,9 \\
\hline & & & & & Más de 8 & 0,2 & Más de 8 & 3,6 \\
\hline \multirow{3}{*}{$\begin{array}{l}\text { Claustro de } \\
\text { Universitario }\end{array}$} & \multirow{3}{*}{20,2} & \multirow{3}{*}{5,2} & \multirow{3}{*}{18} & \multirow{3}{*}{6,7} & $1-4$ & 15,6 & $1-4$ & 2,3 \\
\hline & & & & & $5-8$ & 5,7 & $5-8$ & 1,4 \\
\hline & & & & & Más de 8 & 7,6 & Más de 8 & 2,7 \\
\hline \multirow{3}{*}{$\begin{array}{c}\text { Claustro } \\
\text { de doctores }\end{array}$} & \multirow{3}{*}{6,5} & \multirow{3}{*}{0,2} & \multirow{3}{*}{10,6} & \multirow{3}{*}{0,7} & $1-4$ & 3 & $1-4$ & 1,1 \\
\hline & & & & & $5-8$ & 2,2 & $5-8$ & - \\
\hline & & & & & Más de 8 & 5,8 & Más de 8 & - \\
\hline \multirow{3}{*}{$\begin{array}{c}\text { Comisión de } \\
\text { Garantías al } \\
\text { universitario }\end{array}$} & \multirow{3}{*}{1,4} & \multirow{3}{*}{7} & \multirow{3}{*}{1,2} & \multirow{3}{*}{6,5} & $1-4$ & 2 & $1-4$ & 7,1 \\
\hline & & & & & $5-8$ & 0,2 & $5-8$ & 2,2 \\
\hline & & & & & Más de 8 & - & Más de 8 & 1,1 \\
\hline
\end{tabular}


- Cargos de dirección o coordinación de otras actividades docentes

La dirección o coordinación de distintas actividades docentes es una tarea llevada a cabo por una importante proporción de profesorado, siendo muy similar la participación de profesores y profesoras en las mismas.
En cuanto al tipo de actividad, los profesores afirman haber dirigido o coordinado más Cursos de Doctorado, Master y Comisiones de Garantías que sus compañeras. Sin embargo, éstas se han encargado en mayor medida de las labores de coordinación o dirección de congresos y jornadas científicas.

Tabla 36

Participación en cargos de dirección o coordinación de otras actividades docentes

\begin{tabular}{|l|c|c|c|}
\hline \multicolumn{2}{|l|}{ Otras actividades docentes } & Hombres & Mujeres \\
\hline \multirow{3}{*}{ Participación } & Sí & 44,6 & 40,3 \\
\cline { 2 - 4 } & No & 39,3 & 40,3 \\
\cline { 2 - 4 } & NC & 79 & 19,4 \\
\hline
\end{tabular}

Tabla 37

Tipo de actividades docentes que se han dirigido o coordinado

\begin{tabular}{|c|c|c|c|c|c|c|c|c|}
\hline \multirow{2}{*}{ Cursos } & \multicolumn{2}{|c|}{ E elpasado } & \multicolumn{2}{|c|}{ Atuamente } & \multicolumn{4}{|c|}{$\mathbf{N}^{\circ}$ de a! os } \\
\hline & bmbes & Mujeres & binbes & Mujeres & bImb & & Mu & \\
\hline \multirow{3}{*}{ Doctorado } & \multirow{3}{*}{$11,7 \%$} & \multirow{3}{*}{$8,5 \%$} & \multirow{3}{*}{$8,6 \%$} & \multirow{3}{*}{$5,7 \%$} & $1-5$ & 8,7 & $1-5$ & 7,6 \\
\hline & & & & & $6-10$ & 3,8 & $6-10$ & 0,7 \\
\hline & & & & & Más de 10 & 1,6 & Más de 10 & 1,1 \\
\hline \multirow{3}{*}{ Master } & \multirow{3}{*}{$4,5 \%$} & \multirow{3}{*}{$4 \%$} & \multirow{3}{*}{$3,1 \%$} & \multirow{3}{*}{$2,2 \%$} & $1-5$ & 4,2 & $1-5$ & 3,1 \\
\hline & & & & & $6-10$ & 0,6 & $6-10$ & 0,4 \\
\hline & & & & & Más de 10 & 0,2 & Más de 10 & - \\
\hline \multirow{3}{*}{$\begin{array}{l}\text { Otros cursos } \\
\text { de postgrado }\end{array}$} & \multirow{3}{*}{$8,6 \%$} & \multirow{3}{*}{$10 \%$} & \multirow{3}{*}{$4,5 \%$} & \multirow{3}{*}{$3,7 \%$} & $1-5$ & 6,7 & $1-5$ & 7,8 \\
\hline & & & & & $6-10$ & 1,8 & $6-10$ & 0,4 \\
\hline & & & & & Más de 10 & 0,2 & Más de 10 & 0,2 \\
\hline \multirow{3}{*}{$\begin{array}{c}\text { Comisión de } \\
\text { Garantías }\end{array}$} & \multirow{3}{*}{$26,8 \%$} & \multirow{3}{*}{$25,9 \%$} & \multirow{3}{*}{$11 \%$} & \multirow{3}{*}{$9,5 \%$} & $1-5$ & 17,6 & $1-5$ & 16,8 \\
\hline & & & & & $6-10$ & 2,6 & $6-10$ & 1,7 \\
\hline & & & & & Más de 10 & 1,8 & Más de 10 & 0,2 \\
\hline \multirow{3}{*}{$\begin{array}{l}\text { Comisión de } \\
\text { Garantías }\end{array}$} & \multirow{3}{*}{$6,7 \%$} & \multirow{3}{*}{$7,7 \%$} & \multirow{3}{*}{$4,7 \%$} & \multirow{3}{*}{$6,7 \%$} & $1-5$ & 6,8 & $1-5$ & 5,2 \\
\hline & & & & & $6-10$ & 1,4 & $6-10$ & 1,6 \\
\hline & & & & & Más de 10 & 0,6 & Más de 10 & 0,6 \\
\hline
\end{tabular}




\section{Conclusiones}

Los resultados que hemos ido comentando evidencian una menor discriminación en función del género de lo que en principio podía parecer previsible, de acuerdo con las conclusiones que se pueden extraer de otros estudios realizados sobre la temática. Sin embargo, como se ha podido apreciar en los resultados que hemos ido presentando, las docentes del siglo XXI no han conseguido alcanzar todavía una plena igualdad en el acceso a los máximos cargos académicos, de gestión y responsabilidad en el ámbito universitario, aunque legalmente la institución universitaria reconozca la igualdad de ambos colectivos para ocuparlos. Ejemplos de ello hemos ido poniendo de manifiesto a lo largo del artículo y, de modo especial en nuestro estudio, donde se ha evidenciado que el profesorado varón:

- $\quad$ Está más presente que sus compañeras en aquellas categorías profesionales de mayor reconocimiento y prestigio (Catedráticos de universidad).

- $\quad$ Aspira, en mayor medida que éstas, a culminar su carrera docente como Catedrático.

- Realiza más frecuentemente que el colectivo docente femenino otras actividades profesionales además de la docencia universitaria.

- Manifiesta sentirse más capaz y muestra un mayor interés por desempeñar cargos de dirección y gestión, lo que explica que haya una mayor tendencia, por parte del colectivo docente masculino, a la participación en aquellos órganos colegiados y unipersonales que exigen mayor dedicación de tiempo y esfuerzo, y con los que, a su vez, obtiene más reconocimiento profesional.
Creemos que en la mayoría de los casos, es el entorno social y el rol asumido tradicionalmente por la mujer, relacionado con las responsabilidades familiares y tareas domésticas, lo que le lleva a sentirse en desigualdad de condiciones cuando tiene que competir con sus colegas universitarios. Así, por ejemplo, hemos visto cómo el esfuerzo que supone para muchas profesoras el tener que compaginar las actividades docentes e investigadoras con tareas propiamente familiares, les lleva a relegar a lugares más secundarios entre sus prioridades, su participación en cargos de dirección y gestión o la realización de otras actividades profesionales. Algunas, incluso, perciben una incompatibilidad entre familia y desarrollo de la carrera profesional, lo que quizá explica que compartan su vida en pareja en menor medida que el colectivo varón, o que se decanten por prolongar o renunciar a la maternidad.

Creemos que más que una cuestión de desigualdad de oportunidades entre géneros, la razón puede estar en el hecho de que la escala de valores en uno y otro colectivo difiere. Sin ser nuestra pretensión el hacer generalizaciones, parece que la mujer tiende a tener prioridades más relacionadas con la familia, mientras que el hombre suele considerar prioritario su trabajo. En la base de esta escala de valores diferentes, subyace toda una serie de tradiciones y roles socialmente muy arraigados, que se van interiorizando desde los primeros años de vida, trayendo consigo que la educación de niños y niñas no siempre se realice bajo los parámetros de la distribución equitativa de las tareas domésticas y familiares. En este sentido, valdría la pena preguntarse si no es en estos primeros momentos de socialización y asunción de valores y pautas de comportamiento, en gran medida basados en la observación de los propios padres, cuando se determina la futura igualdad de oportunidades entre hombres y mujeres. 


\section{Notas}

1. Esta es la razón de la restricción temporal de nuestro examen, centrándolo en el periodo comprendido entre los años 1995 y 2000 . La escasa variación interanual de las cifras nos ha llevado a la presentación de la información tomando como punto de referencia los datos relativos a los cursos académicos 1995-96, 1997-98 y 1999-00.

2. El equipo de investigación está formado por las siguientes profesoras: Dña. $\mathrm{M}^{\mathrm{a}}$ del Pino Lecuona, Dña. Ana García-Valcárcel, Dña. Azucena Hernández y Dña. Maㅡ Cruz Sánchez (Proyecto I+D+I:87/00 titulado: Mujer y trabajo: Igualdad de oportunidades en función del género en el acceso y ejercicio de la función docente universitaria, presentado en Salamanca, 2002).

\section{Referencias bibliográficas}

Almarcha, A., González, B. y González, C. "Cambio y desigualdad en el profesorado universitario”. Reis, $\mathrm{n}^{\circ} 66,117$ 139. 1994.

Andino, S. "Análisis comparativo sobre el alumnado de postgrado". En $\mathrm{M}^{\mathrm{a}} \mathrm{A}$. García León y M. García Cortazar (codir.). Las académicas. Profesorado universitario y género (193-138). Madrid: Ministerio de Trabajo y Asuntos Sociales/ Instituto de la Mujer. 2001.

Barbera, E., Lafuente, Mํㅗ. y Sarrió, M. La promoción profesional de las mujeres en la universidad. Valencia: Promolibro. 1998.

Casas, J. I. "Indicadores sobre la situación laboral de la mujer”. En M. Álvaro Page (coord.). Propuesta de un sis- tema de indicadores sociales de igualdad entre géneros (207-246). Madrid: Ministerio de Asuntos Sociales. Instituto de la Mujer. 1994.

Centro de Investigación y Documentación Educativa (CIDE). La presencia de las mujeres en el sistema educativo. Madrid: MEC/CIDE. 1988.

Centro de Investigación y Documentación Educativa (CIDE). Las desigualdades de la educación en España. Madrid: MEC/CIDE. 1992.

Centro de Investigación y Documentación Educativa (CIDE). Las mujeres en el sistema educativo. Madrid: MEC/CIDE. 2001.

Cirujano, P. "Hombres y mujeres en la Universidad Española: Panorama esta-

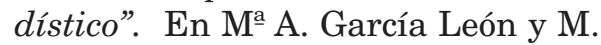
García Cortazar (codir.). Las académicas. Profesorado universitario y género (217-260). Madrid: Ministerio de Trabajo y Asuntos Sociales/ Instituto de la Mujer.2001.

Fernández, C. "La mujer en la universidad española: docencia, investigación y poder. Datos y aspectos”. Revista de Educación, nº 290, pp.161-171. 1989.

Grañeras, M., Gordo, J., Lamelas, R., Villa, N, Regil, N. Las desigualdades de la educación en España, II. Madrid: MEC/CIDE. 1999.

Instituto de la Mujer. Estudio sobre los avances, estancamientos y retrocesos de las mujeres en el ámbito docente. Madrid: Instituto de la Mujer. 1996. 
Instituto Nacional de Estadística. Estadística de la enseñanza en España. Madrid:Instituto Nacional de Estadística.1993

Langevin, A. "Trayectorias femeninas en la enseñanza superior”. En C. Zanz Rueda (coord.). Invisibilidad y presencia (291-309). Seminario Internacional Género y Trayectoria del profesorado universitario. Madrid: Instituto de Investigaciones Feministas de la Universidad Complutense de Madrid /Consejería de Presidencia de la Comunidad de Madrid. 1995.

Martín Tabernero, Mํㅡ. F. y Delgado Álverez, C. Habilidades directivas: Estudio de sesgo de género en instrumentos de evaluación. Madrid: Fundación Mapfre: Cuadernos de la fundación, nº 53. 2000.

Martín Rojo, L. y Gómez Esteban, C. “Imágenes de la mujer en situaciones de competitividad laboral". En C. Brullet Tenas y P. Carrasquer Oto (comp.). Sociología de las relaciones de género (129-136). Madrid: Ministerio de Trabajo y Asuntos Sociales. Instituto de la Mujer. 1996.

Müller, U. "Mujeres en la academia: Barreras al acceso". En C. Zanz Rueda (coord.). Invisibilidad y presencia (211220). Seminario Internacional "Género y trayectoria del profesorado universitaria”. Madrid: Instituto de Investigaciones Feministas de la Universidad Complutense de Madrid /Consejería de Presidencia de la Comunidad de Madrid. 1995.

Muñoz, B. Mujer e institución universitaria en occidente en la Europa del siglo XXI: Problemas y posibilidades. Congreso internacional: Mujeres e institución universitaria en occidente. Conocimiento, investigación y roles de género. Santiago de Compostela: Universidad de Santiago de Compostela. 171-190. 1996.

Sutherland, M. "Women in higher education: Effects of crises and change". En G.P. Kelly y S. Slaughter (ed.). Women's higher education in comparative perspective (131-144). USA: Kluwer Academic Publisher. 1991.

Torrens Calle, P. La evolución de la participación de la mujer en la Universidad de Santiago: 1975-1995. En Congreso Internacional: Mujeres e institución universitaria en occidente. Conocimiento, investigación y roles de género (245-256). Santiago de Compostela: Universidad de Santiago. 1996.

UNIFEM (2000): El progreso de las mujeres en el mundo 2000. Disponible en: http://www.unifem.undp.org./ progressww/2000/progresssp.html 
